\title{
Inhibition of Skeletal Muscle S1-Myosin ATPase by Peroxynitrite ${ }^{\dagger}$
}

\author{
Teresa Tiago, ${ }^{\ddagger}$ Sónia Simão, ${ }^{\ddagger}$ Manuel Aureliano, ${ }^{\ddagger}$ Francisco Javier Martín-Romero, ${ }^{\S}$ and Carlos Gutiérrez-Merino*, \\ Centre for Marine Sciences, Departamento de Química e Bioquímica, FCT, Universidade do Algarve 8005-139, Faro, Portugal, \\ and Departamento de Bioquímica y Biología Molecular, Facultad de Ciencias, Universidad de Extremadura, \\ 06071 Badajoz, Spain
}

\begin{abstract}
Exposure of myosin subfragment 1 (S1) to 3-morpholinosydnonimine (SIN-1) produced a time-dependent inhibition of the F-actin-stimulated $\mathrm{S} 1 \mathrm{Mg}^{2+}$-ATPase activity, reaching $50 \%$ inhibition with $46.7 \pm 8.3 \mu \mathrm{M}$ SIN-1 for $8.7 \mu \mathrm{M} \mathrm{S} 1$, that is, at a SIN-1/S1 molar ratio of approximately 5.5 . The inhibition was due to the peroxynitrite produced by SIN-1 decomposition because (1) decomposed SIN-1 was found to have no effect on S1 ATPase activity, (2) addition of SIN-1 in the presence of superoxide dismutase and catalase fully prevented inhibition by SIN-1, and (3) micromolar pulses of chemically synthesized peroxynitrite produced inhibition of F-actin-stimulated $\mathrm{S} 1 \mathrm{Mg}^{2+}$-ATPase activity. In parallel, SIN-1 produced the inhibition of the nonphysiological $\mathrm{Ca}^{2+}$-dependent and $\mathrm{K}^{+} /$EDTA-dependent S1 ATPase activity of $\mathrm{S} 1$ and, therefore, suggested that the inhibition of F-actin-stimulated $\mathrm{S} 1 \mathrm{Mg}^{2+}$-ATPase activity is produced by the oxidation of highly reactive cysteines of $\mathrm{S} 1\left(\mathrm{Cys}_{707}\right.$ and $\left.\mathrm{Cys}_{697}\right)$, located close to the catalytic center. This point was further confirmed by the titration of S1 cysteines with 5,5'-dithiobis(2nitrobenzoic acid) and by the parallel decrease of $\mathrm{Cys}_{707}$ labeling by 5-(iodoacetamido)fluorescein, and it was reinforced by the fact that other common protein modifications produced by peroxynitrite, for example, protein carbonyl and nitrotyrosine formation, were barely detected at the concentrations of SIN-1 that produced more than $50 \%$ inhibition of the F-actin-stimulated S1 $\mathrm{Mg}^{2+}$-ATPase activity. Differential scanning calorimetry of S1 (untreated and treated with different SIN-1 concentrations) pointed out that $\mathrm{SIN}-1$, at concentrations that generate micromolar peroxynitrite fluxes, impaired the ability of ADP $\cdot \mathrm{V}_{1}$ to induce the intermediate catalytic transition state and also produced the partial unfolding of S1 that leads to an enhanced susceptibility of S1 to trypsin digestion, which can be fully protected by $2 \mathrm{mM} \mathrm{GSH}$.
\end{abstract}

Impairment of muscle contraction has been reported upon exposure of muscle cells to chronic oxidative stress conditions, and it has been proposed that it is, at least in part, the result of oxidative modification of myofibril proteins $(1,2)$. A high sensitivity of muscle myofibrils to free-radicalmediated oxidative stress had been noticed by Nagasawa et al. (3), who showed that skeletal muscle actin and myosin become oxidized in vivo following Fe-nitrilotriacetate treatment in rats, an experimental model for iron overload. Furthermore, Andrade et al. (4) have shown that exposure of muscle fibers to low peroxide concentrations induced an altered cross-bridge kinetics. Because peroxynitrite is a major oxidative agent in ischemia/reperfusion insults such as heart infarct or atrial fibrillation $(1,5,6)$ and produces a reaction likely to be irreversible in vivo, the nitration of protein tyrosines to 3-nitrotyrosine (7-9), the level of protein nitration has gained acceptance as a fingerprint of in vivo peroxynitrite-mediated oxidative-stress damage $(8)$. Recent studies have shown that myosin is one

† This work was supported by Grant 3PR05A078 from the Junta de Extremadura (to C.G.-M.), by Joint Spanish-Portuguese Grant HP2004-0080 (to C.G.-M. and M.A.), and by the POCTI program financed through FEDER for research project 38191/QUI/2001 (to M.A.). T.T. is a recipient of a postdoctoral fellowship (SFRH/BPD/ 20777/2004) from the Portuguese Foundation for Science and Technology (FCT). of the muscle proteins showing higher levels of 3-nitrotyrosine after atrial fibrillation $(1,6)$ and aging $(10)$. However, despite muscle myosin being a major and particularly relevant component of myofibrils, myosin sensitivity to peroxynitrite-induced oxidative stress and the functional and structural consequences of its modification by peroxynitrite have not been worked out and deserve to be studied.

Peroxynitrite is a strong oxidant $\left(E^{0^{\prime}}=1.2-1.4 \mathrm{~V}(11)\right)$ and can directly produce the oxidation of protein cysteines to thiyl radicals, disulfides, and eventually sulfenic acid (12, 13), although at physiological $\mathrm{pH}$, the two-electron oxidation leading to disulfides predominates (8), and to a lesser extent, peroxynitrite can oxidize other amino acids leading to protein carbonyl formation (14). Protein-cysteine oxidation by peroxynitrite has been shown to cause the inhibition of sarcoplasmic-reticulum $\mathrm{Ca}^{2+}$ ATPase $(15,16)$. In addition, peroxynitrite can modify proteins by acting through radicals generated during its spontaneous decomposition in biochemical buffers and biological fluids, particularly, $\mathrm{HO} \cdot$ and $\mathrm{NO}_{2} \cdot$, a reaction pathway that is potentiated by the presence of bicarbonate, which upon reaction with peroxynitrite leads to the production of carboxylate radical $\mathrm{CO}_{3}{ }^{-}(17,18)$. One characteristic product of this reaction pathway in proteins is 3 -nitrotyrosine. It has been reported that nitration of tyrosines close to the catalytic center can at least in part account for the inhibition of the activity of several enzymes by peroxynitrite (9). In addition, oxidation of amino acid side chains leading to protein carbonyls can also be produced through this radical pathway (19). 
SIN $-1^{1}$ has been widely used to mimic the effects of chronic exposure of cells in culture to peroxynitrite oxidative stress $(20,21)$. SIN-1 slowly decomposes in neutral and weakly alkaline water solutions, releasing nitric oxide and superoxide anion (22), which react with each other to produce peroxynitrite with a second-order rate constant of $4-7 \times$ $10^{9} \mathrm{M}^{-1} \cdot \mathrm{s}^{-1}$, close to the diffusion limit for chemical reactions $(8,23)$. Because of the short lifetime of peroxynitrite at physiological $\mathrm{pH}$, less than $1 \mathrm{~s}$ in buffer solutions at $\mathrm{pH} 7(8)$ and less than $0.1 \mathrm{~s}$ in cytosol $(11,24)$, and because synthetic peroxynitrite needs to be stored in highly alkaline solutions (i.e., $1.5 \mathrm{M} \mathrm{NaOH}$ ) (12), SIN-1 offers clear advantages over synthetic peroxynitrite for carrying out studies on the effects of the exposure of cells and subcellular components to submicromolar or micromolar fluxes of peroxynitrite at a duration of $30 \mathrm{~min}$ to $2 \mathrm{~h}$ (25), an oxidative stress that can be attained during inflammation and ischemia/ reperfusion episodes $(8,26)$. Moreover, the kinetics of peroxynitrite generation and the peroxynitrite concentration attained in the solution during SIN-1 decomposition can be reliably monitored in the buffered solutions commonly used for biochemical studies with isolated subcellular components (25).

The head segment of myosin, named subfragment 1 or $\mathrm{S} 1$, can be produced by limited chymotrypsin digestion and purified by following well-established protocols $(27,28)$. S1 contains the binding sites for ATP and actin and is the protein domain responsible for the myosin-ATPase activity during muscle contraction (29). During myosin-ATPase activity, S1 cycles through an intermediate state $\mathrm{M}^{* *} \cdot \operatorname{ADP} \cdot \mathrm{P}_{\mathrm{i}}(30,31)$. Vanadate inhibits myosin-ATPase activity by forming, in the absence of actin, a very stable complex with MgADP that mimics this transition $\mathrm{M}^{* *} \cdot \mathrm{ADP} \cdot \mathrm{P}_{\mathrm{i}}$ intermediate state (30). The addition of $\mathrm{ADP} \cdot \mathrm{V}_{1}$ and $\mathrm{ADP} \cdot \mathrm{AlF}_{4}(200 \mu \mathrm{M})$ along with a short incubation time (usually less than $30 \mathrm{~min}$ ) has been used to mimic the intermediate activated $\mathrm{M}^{* * *} \cdot \mathrm{ADP} \cdot \mathrm{P}_{\mathrm{i}}$ state $(32-34)$.

In this work, we report that exposure of S1 to synthetic peroxynitrite or to submicromolar and micromolar peroxynitrite concentrations generated with SIN-1 produced strong inhibition of the F-actin-stimulated $\mathrm{S} 1 \mathrm{Mg}^{2+}$-ATPase activity, which correlated with the impairment of the ability of S1 to reach the obligatory catalytic cycle intermediate state $\mathrm{M}^{* *}$. $A D P \cdot P_{i}$ and the protein unfolding at the highest SIN-1 concentrations studied. The relevance of cysteine oxidation, 3-nitrotyrosines, and protein carbonyl formation to $\mathrm{S} 1$ inhibition induced by the exposure of S1 to peroxynitrite has also been studied.

\section{MATERIALS AND METHODS}

Purification of Myosin and Preparation of S1. Myosin and $\mathrm{S} 1$ have been prepared as indicated by Tiago et al. (35).

\footnotetext{
${ }^{1}$ Abbreviations: ADP $\cdot \mathrm{V}_{1}$, adenosine $5^{\prime}$-diphosphate-orthovanadate DSC, differential scanning calorimetry; DNPH, 2,4-dinitrophenylhydrazine; DTNB, 5,5'-dithiobis(2-nitrobenzoate); DTT, dithiothreitol; EDTA, ethylenediaminetetraacetic acid; GSH, reduced glutathione; Hepes, 4-(2-hydroxyethyl)-1-piperazineethanesulfonic acid; $\mathrm{IC}_{50}$, inhibitor concentration required to produce $50 \%$ inhibition; IAF, 5-(iodoacetamido)fluorescein; $\mathrm{P}_{\mathrm{i}}$, inorganic phosphate; $\mathrm{M}^{* * *} \cdot \mathrm{ADP} \cdot \mathrm{P}_{\mathrm{i}}$, intermediate transient state of F-actin-stimulated myosin-ATPase activity; S1, myosin subfragment 1; SDS, sodium dodecyl sulfate; SIN-1, 3-morpholinosydnonimine; SOD, superoxide dismutase; TCA, trichloroacetic acid; Tris, tris(hydroxymethyl)aminomethane hydrochloride; $\mathrm{U}$, amount of enzyme that releases $1 \mu \mathrm{mol}$ of product per minute.
}

Briefly, myosin was prepared from leg and dorsal whiterabbit skeletal muscle, as previously described by Pires et al. (36). Subfragment 1 (S1) was prepared by the chymotryptic digestion of myosin according to Margossian and Lowey (28). F-Actin was prepared from an acetone powder of rabbit skeletal muscle as described by Pardee and Spudich (37). Protein concentrations were determined spectrophotometrically by using extinction coefficients of $E^{1 \%}{ }_{280}=5.7$ $\mathrm{cm}^{-1}$ for myosin, $E^{1 \%}{ }_{280}=7.5 \mathrm{~cm}^{-1}$ for $\mathrm{S} 1$, and $E^{1 \%}{ }_{290}=$ $11.5 \mathrm{~cm}^{-1}$ for actin. The molecular masses used were 500 , 115 , and $42 \mathrm{kDa}$ for myosin, S1, and actin, respectively.

Measurement of Peroxynitrite Produced during SIN-1 Decomposition and Preparation of Synthetic Peroxynitrite. The production of peroxynitrite during SIN-1 decomposition has been calculated from the kinetics of oxidation of NADH, continuously monitored by the decay of absorbance at 340 $\mathrm{nm}$ and the efficiency of peroxynitrite detection by NADH (80\% in our assays), as in Martín-Romero et al. (25) and Gutiérrez-Martín et al. (21). As described therein, the time course of the total peroxynitrite released by SIN-1 can be obtained by integrating the area below the curve up to different times, and the peroxynitrite flux per minute at different times during SIN-1 decomposition can be obtained from the slope of the plot of total peroxynitrite versus time.

Peroxynitrite was synthesized according to the method described by Radi et al. (12) and briefly outlined in a previous study (38). The peroxynitrite solution was split into small aliquots and frozen at less than $-25{ }^{\circ} \mathrm{C}$ until use. Peroxynitrite concentration was measured spectrophotometrically in aliquots defrosted immediately before the experiments reported in this article using an extinction coefficient of $1670 \mathrm{M}^{-1} \cdot \mathrm{cm}^{-1}$ at $302 \mathrm{~nm}$ in $1.5 \mathrm{M} \mathrm{NaOH}(19)$.

Measurement of $\mathrm{Mg}^{2+}$-ATPase, $\mathrm{Ca}^{2+}$-ATPase, and $\mathrm{K}^{+}$/ EDTA-ATPase Activities. Steady-state assays of $\mathrm{Mg}^{2+}-$ ATPase and actin-activated S1 ATPase were measured spectrophotometrically at $25^{\circ} \mathrm{C}$ using the coupled-enzymepyruvate-kinase/lactate-dehydrogenase assay (39) with the following reaction mixture: $20 \mathrm{mM}$ Hepes ( $\mathrm{pH} 7.0), 2.5 \mathrm{mM}$ $\mathrm{MgCl}_{2}, 2 \mathrm{mM}$ ATP, $0.42 \mathrm{mM}$ phosphoenolpyruvate, 0.375 $\mathrm{mM} \mathrm{NADH}, 18 \mathrm{U}$ of lactate dehydrogenase, and $18 \mathrm{U}$ of pyruvate kinase, as described in the literature (35). F-Actinstimulated $\mathrm{S} 1 \mathrm{Mg}^{2+}$-ATPase activity was measured by supplementing the previous assay medium with a nearly 4.4fold molar excess of F-actin over S1, unless indicated otherwise $(2 \mu \mathrm{M}$ F-actin and $0.45 \mu \mathrm{M} \mathrm{S} 1)$, and we obtained an average activity of $1.64 \pm 0.05 \mu \mathrm{mol}$ of product $\mathrm{min}^{-1}$ $(\mathrm{mg} \text { of S1) })^{-1}(n>10 \mathrm{~S} 1$ and F-actin preparations). Under these experimental conditions, F-actin stimulated the basal $\mathrm{Mg}^{2+}$-ATPase activity of $\mathrm{S} 1$ approximately 20 -fold, that is, the basal $\mathrm{S} 1 \mathrm{Mg}^{2+}$-ATPase activity was on average $0.085 \pm$ $0.005 \mu \mathrm{mol}$ of product $\min ^{-1}(\mathrm{mg} \text { of S1) })^{-1}$.

Nonphysiological ATPase activities $\left(\mathrm{Ca}^{2+}\right.$ - and $\mathrm{K}^{+} /$EDTAATPase) of S1 were measured by the determination of inorganic phosphate release following the method of Fiske and Subbarow (40), as in Tiago et al. (35). The assays were carried out at room temperature in $50 \mathrm{mM}$ Tris- $\mathrm{HCl}(\mathrm{pH}$ 7.9), $2.5 \mathrm{mM}$ ATP, and either $0.23 \mathrm{M} \mathrm{KCl}$ and $2.5 \mathrm{mM} \mathrm{CaCl}_{2}$ for $\mathrm{Ca}^{2+}$-ATPase or $0.6 \mathrm{M} \mathrm{KCl}$ and $1 \mathrm{mM}$ EDTA for $\mathrm{K}^{+} /$ EDTA-ATPase activities, using $0.1 \mathrm{mg}$ of $\mathrm{S} 1 / \mathrm{mL}(0.87 \mu \mathrm{M}$ S1).

DSC Measurements. DSC measurements were done as described by Merino and Gutiérrez-Merino (41). Briefly, 
scanning-calorimetry measurements were carried out using a MicroCal MC-2 differential scanning calorimeter, operated at a scanning rate of $60{ }^{\circ} \mathrm{C} / \mathrm{h}$ under nitrogen pressure of $1.5-2 \mathrm{~kg} / \mathrm{cm}^{2}$ during the scan. To minimize the $\mathrm{pH}$ change due to the large enthalpy of protonation of Tris during the temperature scan, the buffer used for $\mathrm{S} 1$ treatments with SIN-1 was supplemented with $50 \mathrm{mM} \mathrm{P}_{\mathrm{i}}$ before the samples were loaded in the differential scanning calorimeter (DSC buffer: $50 \mathrm{mM} \mathrm{P}, 10 \mathrm{mM}$ Tris, and $25 \mathrm{mM} \mathrm{KCl} \mathrm{(pH} \mathrm{7.35)).}$ All of the scans reported in this article are representative of experiments done in triplicate with, at least, duplicate S1 preparations. The analysis of the calorimetric data was carried out with Origin software developed by MicroCal (Northampton, MA). The curve fitting used Marquadt methods on the basis of nonlinear least squares, which improved the estimates for each parameter using an iterative process until there was no further improvement of the fit (minimum value $\chi^{2}$ ).

Measurements of Cys Oxidation, Nitro-Tyr Formation, and Protein Carbonyls. The titration of S1 cysteines was done with DTNB, as indicated in previous works $(21,42)$, using an extinction coefficient at $412 \mathrm{~nm}$ of $12000 \mathrm{M}^{-1} \cdot \mathrm{cm}^{-1}$ for the colored product, thionitrophenolate. S1 cysteines were measured with $0.5 \mathrm{mM}$ DTNB and an S1 concentration of $0.5 \mathrm{mg}$ of protein/mL in $10 \mathrm{mM}$ Tris and $25 \mathrm{mM} \mathrm{KCl}(\mathrm{pH}$ 8.5). The increase in absorbance at $412 \mathrm{~nm}$ was continuously recorded for $10 \mathrm{~min}$ and then treated with $1 \% \mathrm{SDS}$ and heated for $5 \mathrm{~min}$ at $80^{\circ} \mathrm{C}$, and the absorbance was measured after cooling for $15-30 \mathrm{~min}$ until a steady value was reached.

The extent of nitrotyrosine formation was measured spectrophotometrically, using an extinction coefficient at 415 $\mathrm{nm}$ of $2800 \mathrm{M}^{-1} \cdot \mathrm{cm}^{-1}$, determined from measurements of pure 3-nitrotyrosine solutions prepared by weight in the buffer used for the treatment of S1 with SIN-1. In addition, nitrotyrosine formation was also assessed by Western blotting of SDS-PAGE as indicated by Gutiérrez-Martin et al. (43). SDS-PAGE of S1 was performed in $12 \%$ polyacrylamide gel.

Protein carbonyl formation was measured spectrophotometrically using DNPH as in Dalle-Donne et al. (44). Briefly, the protein sample $(2 \mathrm{mg} / \mathrm{mL})$ was divided into two $1 \mathrm{~mL}$ aliquots: a test and a blank. The test aliquot was reacted with $1 \mathrm{~mL}$ of $10 \mathrm{mM} \mathrm{DNPH}$ in $2 \mathrm{M} \mathrm{HCl}$, and the blank aliquot was reacted only with $2 \mathrm{M} \mathrm{HCl}$ for $1 \mathrm{~h}$ in the dark at room temperature while vortexing every $10 \mathrm{~min}$. The samples were precipitated with $20 \%$ TCA (final concentration) and centrifuged for $5 \mathrm{~min}$ at $1500 \mathrm{~g}$. The supernatants were discarded and the protein pellets washed once more with $10 \%$ TCA and then washed three times with $1 \mathrm{~mL}$ portions of ethanol/ethyl acetate $(1: 1, \mathrm{v} / \mathrm{v})$. The final pellets were resuspended in $1 \mathrm{~mL}$ of $6 \mathrm{M}$ guanidine hydrochloride (dissolved in $20 \mathrm{mM}$ phosphate buffer, $\mathrm{pH} 2.3$ ) at $37^{\circ} \mathrm{C}$ for 15 min with vortexing. Carbonyl contents were estimated by the difference in absorbance at $366 \mathrm{~nm}$ (test - blank) using a molar absorption coefficient of $22000 \mathrm{M}^{-1} \cdot \mathrm{cm}^{-1}$.

Labeling of S1 at Cys 707 with 5-(Iodoacetamido)fluorescein $(I A F)$. S1 was labeled at $\mathrm{Cys}_{707}$ with IAF as indicated in a previous study (35), following the protocol indicated in the procedure $(34,45)$. Prior to labeling, S1 was first dialyzed against $0.12 \mathrm{M} \mathrm{KCl}$ and $25 \mathrm{mM}$ Tris- $\mathrm{HCl}$ at $\mathrm{pH}$ 8.0. The dialyzed sample was then incubated with a 4-5-fold molar excess of IAF at room temperature for $30 \mathrm{~min}$ in the dark. The unreacted probe was subsequently removed on a
Sephadex G-50 column equilibrated with $0.12 \mathrm{M} \mathrm{KCl}$ and $25 \mathrm{mM}$ Tris- $\mathrm{HCl}$ at $\mathrm{pH} 7.0$.

Measurements of Hydrogen Peroxide. Hydrogen peroxide measurements have been done with an Amplex Red/ horseradish peroxidase assay, as indicated in the Molecular Probes Handbook of Fluorescence Probes and Research Products (9th ed.).

Statistical Analysis of Experimental Results. All of the experimental results have been confirmed with three different $\mathrm{S} 1$ myosin preparations, and for each $\mathrm{S} 1$ myosin preparation, measurements have been done, at least, by duplicate (i.e., $n$ $\geq 6$ for each data point). The data plotted in the Figures are the averages, and the error bars shown are the standard deviations. Lines drawn in the figures of inhibition of the S1 ATPase activities as a function of SIN-1 concentration are the best nonlinear least-squares two-parameter fit to the equation $V=V_{0}-\left(I_{\max }[\mathrm{SIN}-1] / \mathrm{IC}_{50}+[\mathrm{SIN}-1]\right)$, where $I_{\max }$ (the maximum inhibition) and $\mathrm{IC}_{50}$ are the two iterative parameters used for the nonlinear least-squares fit, $V_{0}$ is the ATPase activity before treatment with SIN-1, and $V$ is the ATPase activity after treatment with each SIN-1 concentration.

Chemicals. Chemicals used to prepare buffers were reagent grade. Ammonium metavanadate was purchased from Riedelde-Häen (Germany). ATP, ADP, DNPH, DTNB, DTT, $\mathrm{NADH}, 3$-nitrotyrosine, phosphoenolpyruvate, 3-morpholinosydnonimine (SIN-1), trypsin, and $\alpha$-chymotrypsin were supplied by Sigma Chemical Co. (St. Louis, MO). Pyruvate kinase and lactate dehydrogenase were purchased from Roche Molecular Biochemicals (Mannheim, Germany). 5-(Iodoacetamido)fluorescein (IAF) was supplied by Molecular Probes (Eugene, OR). Monoclonal anti-(3-nitrotyrosine) Ig was purchased from Calbiochem (catalog number 487923, La Jolla, CA), and the secondary IgG conjugated with horseradish peroxidase was supplied by Pierce (Rockford, IL).

GSH and ascorbate solutions were freshly prepared by weight and in the case of GSH brought to $\mathrm{pH} 7.0 \pm 0.1$ with $\mathrm{KOH}$, placed on ice immediately after preparation, and used for experimental handling within $1 \mathrm{~h}$ of preparation. The GSH concentration was routinely tested with DTNB as indicated above for cysteine quantification, and the concentration of ascorbate was monitored with measurements of the absorbance at $265 \mathrm{~nm}$, using an extinction coefficient of $14500 \mathrm{M}^{-1} \cdot \mathrm{cm}^{-1}$ (46).

Decomposed SIN-1 was prepared, leaving a solution of SIN-1 $(1-10 \mathrm{mM})$ in buffer of $10 \mathrm{mM}$ Tris and $25 \mathrm{mM}$ $\mathrm{KCl}(\mathrm{pH} \mathrm{8.5)}$ to stand at room temperature for $12 \mathrm{~h}$.

\section{RESULTS}

Inhibition of S1 ATPase by SIN-1 and Synthetic Peroxynitrite. Incubation of $\mathrm{S} 1$ with $\mathrm{SIN}-1$ resulted in a timedependent inhibition of the F-actin-stimulated $\mathrm{S} 1 \mathrm{Mg}^{2+}$ ATPase activity which closely followed the kinetics of peroxynitrite release upon SIN-1 decomposition (Figure 1). The data shown in Figure 1A fit reasonably well to a singleexponential decay, with a half-time for F-actin-stimulated S1 ATPase inhibition of $37.5 \pm 3.5 \mathrm{~min}$, and a half-time of $42 \pm 2$ min can be derived for SIN-1 decomposition from Figure 1B. The following results further supported the fact that inhibition of F-actin-stimulated S1 $\mathrm{Mg}^{2+}$-ATPase activity 

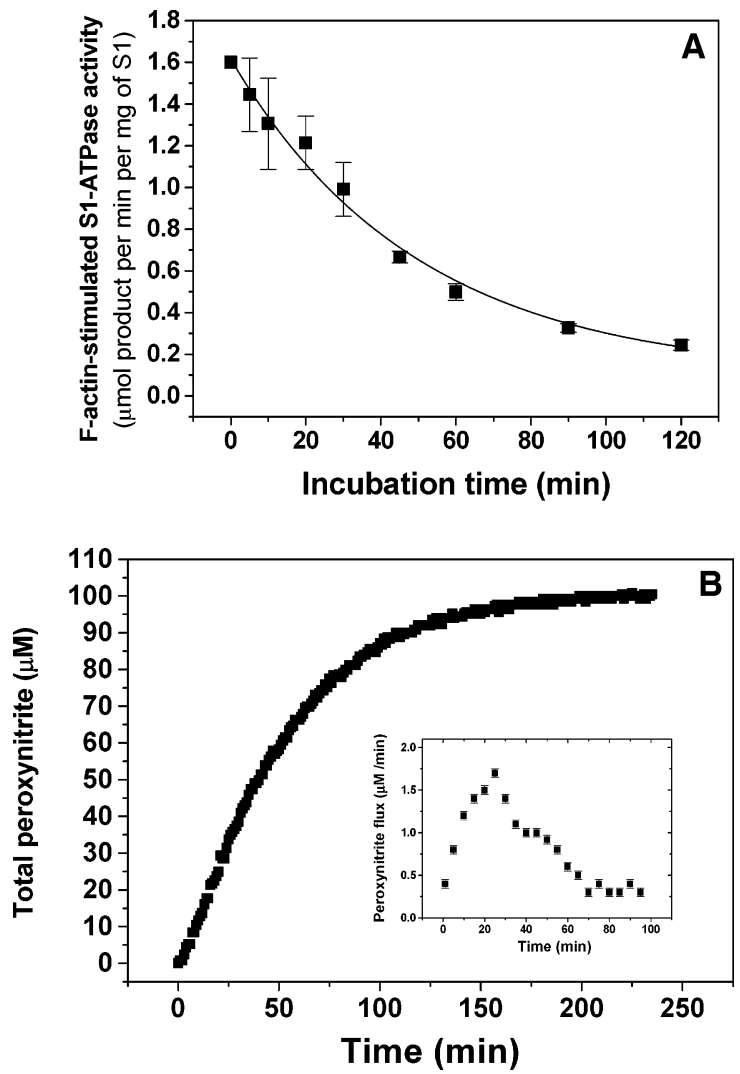

FIGURE 1: Time-dependent inhibition of F-actin-stimulated S1 $\mathrm{Mg}^{2+}$-ATPase activity by SIN-1 (A) and kinetics of peroxynitrite production during SIN-1 decomposition (B). (A) Inhibition of F-actin-stimulated S1 $\mathrm{Mg}^{2+}$-ATPase activity by $100 \mu \mathrm{M} \mathrm{SIN}-1$. S1 $(8.7 \mu \mathrm{M})$ was treated with $100 \mu \mathrm{M}$ SIN-1 in buffer, $10 \mathrm{mM}$ Tris, and $25 \mathrm{mM} \mathrm{KCl}(\mathrm{pH} 8.5)$ at $25^{\circ} \mathrm{C}$, and aliquots of $50 \mu \mathrm{L}$ were pooled at the times indicated in the abscissa and assayed for activity in $1 \mathrm{~mL}$ of reaction medium (indicated in Materials and Methods) supplemented with $2 \mu \mathrm{M}$ F-actin. The line is the best fit of the data to a first-order-exponential-decay function. (B) Kinetics of peroxynitrite production during the decomposition of $100 \mu \mathrm{M}$ SIN-1 in buffer, $10 \mathrm{mM}$ Tris, and $25 \mathrm{mM} \mathrm{KCl} \mathrm{(pH} \mathrm{8.5)} \mathrm{at} 25^{\circ} \mathrm{C}$, measured from the kinetics of NADH oxidation as indicated in Materials and Methods. Inset: Flux rate of peroxynitrite production $(\mu \mathrm{M} / \mathrm{min})$ during the decomposition of $100 \mu \mathrm{M}$ SIN-1, calculated from the slope of the data shown in panel $B$ at different times (with 1 min intervals).

is due to exposure to the peroxynitrite released by SIN-1. (i) Incubation with decomposed SIN-1 did not produce a significant inhibition of this activity, that is, less than $10 \%$ inhibition, and (ii) addition of $3000 \mathrm{U}$ of SOD plus $1500 \mathrm{U}$ of catalase before SIN-1, at concentrations that efficiently remove the superoxide anion and prevent peroxynitrite production as assessed with the NADH assay $(25,47)$, largely protected against the inhibition of this activity. Thus, the results shown in Figure 1 yield an apparent $\mathrm{IC}_{50}$ for F-actinstimulated S1 ATPase of $45 \pm 5 \mu \mathrm{M}$ SIN-1 under the assumption of rapid inhibition upon reaction of S1 with released peroxynitrite. Because the activity assay of S1 treated with peroxynitrite was diluted 20 -fold (from 8.7 to $0.45 \mu \mathrm{M}$ ), the remaining undecomposed SIN-1 added to the assay medium was lower than $5 \mu \mathrm{M}$ for $100 \mu \mathrm{M}$ SIN-1 at the shortest times measured. The possibility that the reaction of S1 with peroxynitrite may elicit a delayed inhibition on $\mathrm{S} 1$ or that remaining SIN-1 added with S1 to the assay medium can react with $\mathrm{F}$-actin or other proteins present in the assay medium (pyruvate kinase or lactate dehydrogenase) could not be excluded solely on the basis of the results in Figure 1, and this encouraged further assessment of the $\mathrm{IC}_{50}$ value for SIN-1.

To experimentally question these points, we have exposed $\mathrm{S} 1$ to different SIN-1 concentrations for $2 \mathrm{~h}$, a time in which more than $95 \%$ of the peroxynitrite derived from SIN-1 decomposition would have already been released (Figure 1B). The results of the inhibition of the F-actin-stimulated S1 $\mathrm{Mg}^{2+}$-ATPase activity with different SIN-1 concentrations are shown in Figure 2A, and the activity remaining after treatment with different SIN-1 concentrations for $2 \mathrm{~h}$ was steady for at least $1 \mathrm{~h}$ after the end of the treatment, thus excluding a slow-developing kinetic-inhibition process. The results shown in Figure 2A yield an $\mathrm{IC}_{50}$ value of $46.7 \pm$ $8.3 \mu \mathrm{M}$ SIN-1, which is identical to the value derived from the results shown in Figure 1 and strongly supports the fact that the inhibition produced by peroxynitrite is due to a fast reaction between peroxynitrite and $\mathrm{S} 1$. Also included in Figure $2 \mathrm{~A}$ is the lack of inhibition by treatment with decomposed SIN-1 and the protection by SOD and (SOD + catalase) against inhibition by $\mathrm{SIN}-1$. As exposure to superoxide anion fluxes of 1 and $2 \mu \mathrm{mol}$ of $\mathrm{O}_{2}{ }^{-}-\mathrm{min}$ (up to a total $200 \mu \mathrm{mol}$ of $\mathrm{O}_{2}{ }^{-}$) generated by xanthine/xanthine oxidase did not inhibit the F-actin-stimulated S1 ATPase activity (results not shown), the protection afforded by SOD can be rationalized only in terms of a blockage in the formation of peroxynitrite, a superoxide anion-derived inhibitor produced during SIN-1 decomposition. These results also excluded a significant contribution of direct inhibition by the nitric oxide released during SIN-1 decomposition below $200 \mu \mathrm{M}$ SIN-1, and the $15-20 \%$ inhibition obtained with $200 \mu \mathrm{M}$ SIN-1 in the presence of SOD plus catalase is in good agreement with the reported inhibition of the F-actinstimulated $\mathrm{S} 1 \mathrm{Mg}^{2+}$-ATPase by millimolar concentrations of nitric oxide-releasing agents (48). In addition, when the $\mathrm{pH}$ of the medium is controlled to avoid a significant increase in $\mathrm{pH}$ (e.g., less than $0.02 \mathrm{pH}$ ), the inhibition of F-actinstimulated $\mathrm{S} 1 \mathrm{Mg}^{2+}$-ATPase activity by SIN-1 was found to be the same in the absence and presence of $25 \mathrm{mM}$ bicarbonate (Figure 2A). Because it has been shown that hydrogen peroxide can be produced from peroxynitrite decomposition in some buffers (49), we have measured the concentration of hydrogen peroxide using the Amplex red assay at different times of exposure and found it to be 3.7 \pm 0.2 and $8.9 \pm 0.3 \mu \mathrm{M}$ after $2 \mathrm{~h}$ of exposure of $\mathrm{S} 1$ to 50 and $200 \mu \mathrm{M}$ SIN-1, respectively. Titration with $\mathrm{H}_{2} \mathrm{O}_{2}$ of the F-actin-stimulated $\mathrm{S} 1 \mathrm{Mg}^{2+}$-ATPase activity yielded an $\mathrm{IC}_{50}$ of $0.1 \mathrm{mM} \mathrm{H}_{2} \mathrm{O}_{2}$ for inhibition of this activity (data not shown), therefore excluding a significant contribution of hydrogen peroxide to the inhibition produced by SIN-1, a conclusion that was also supported by the lack of protection by catalase against inhibition by SIN-1 (Figure 2A).

$\mathrm{S} 1$ can also be inhibited by treatment with single pulses of peroxynitrite added under vortexing (Figure 2B) but with much lower efficiency because of its rapid decomposition before attaining a proper mixing of the solution, as shown by the enhanced inhibition when the same total peroxynitrite is added in pulses of lower concentration (Figure 2B) (43, 50 ). Figure $2 \mathrm{C}$ shows that incubation of $\mathrm{S} 1$ with substrate analogue $\mathrm{Mg}^{2+} \cdot \mathrm{ADP} \cdot \mathrm{V}_{1}$ afforded partial protection against the inhibition of F-actin-stimulated $\mathrm{S} 1 \mathrm{Mg}^{2+}$-ATPase activity by SIN -1 . Therefore, these results suggested that $\mathrm{S} 1$ 

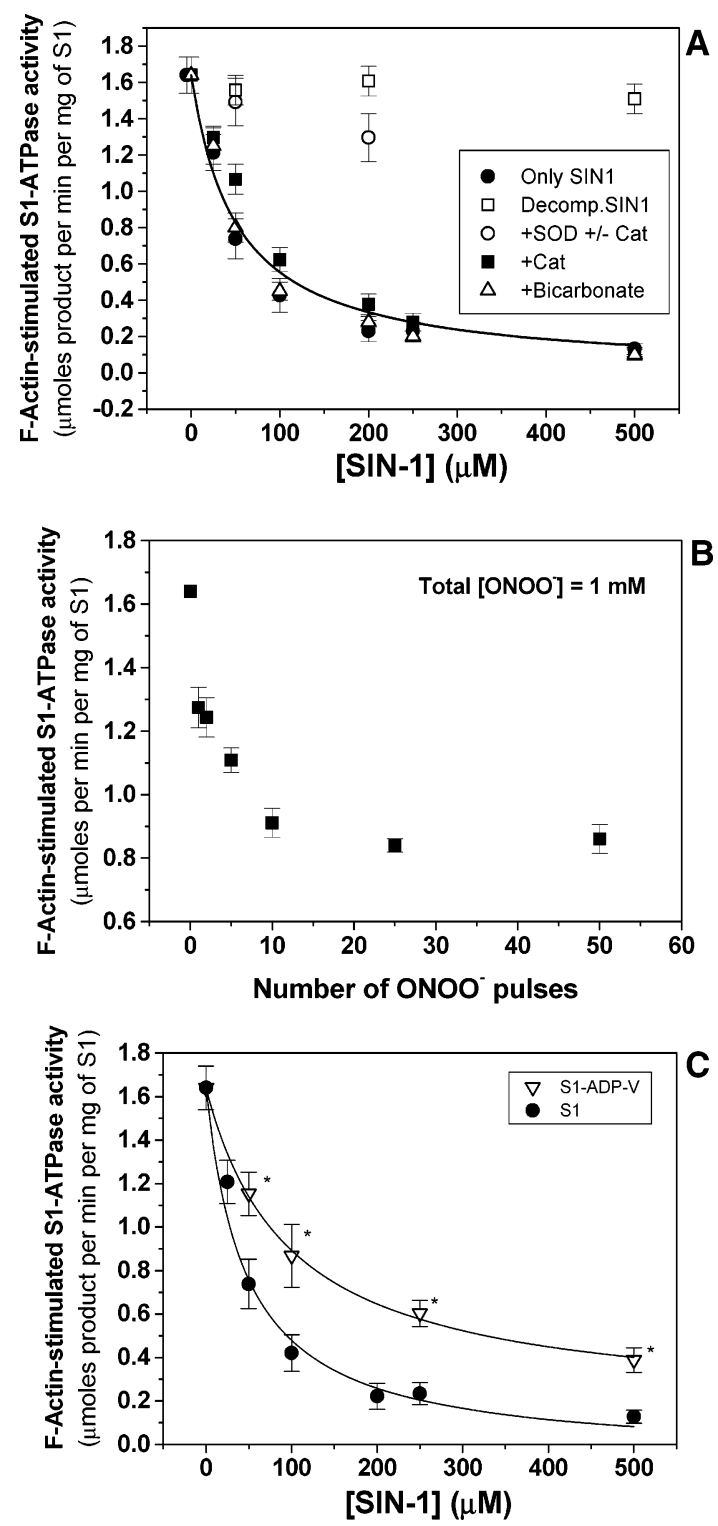

FIGURE 2: Dependence of the inhibition of F-actin-stimulated S1 $\mathrm{Mg}^{2+}$-ATPase activity upon the concentration of SIN-1 (A) and the number of micromolar pulses of synthetic peroxynitrite (B). (A) $\mathrm{S} 1(8.7 \mu \mathrm{M})$ was treated with the concentrations of SIN-1 indicated in the abscissa in buffer, $10 \mathrm{mM}$ Tris, and $25 \mathrm{mM} \mathrm{KCl}$ $(\mathrm{pH} 8.5)$ at $25{ }^{\circ} \mathrm{C}(\mathbf{})$ or in this buffer supplemented with decomposed SIN-1 ( $\square), 3000 \mathrm{U}$ of SOD with or without $1500 \mathrm{U}$ of catalase $(\bigcirc)$, only $1500 \mathrm{U}$ of catalase $(\boldsymbol{\square})$, or $25 \mathrm{mM}$ bicarbonate $(\triangle)$, and after $2 \mathrm{~h}$, the aliquots were pooled for assaying the activity as indicated in the legend of Figure 1A. The effects of catalase and bicarbonate were found to be not statistically significant by an analysis of variance test $(p>0.05)$. (B) $\mathrm{S} 1(8.7 \mu \mathrm{M})$ in buffer, 0.5 $\mathrm{M}$ Tris, and $25 \mathrm{mM} \mathrm{KCl}(\mathrm{pH} 7.2)$ at room temperature was treated with a different number of pulses of synthetic peroxynitrite $\left(\mathrm{ONOO}^{-}\right)$to reach $1 \mathrm{mM}$ total concentration of peroxynitrite. The lowest concentration of peroxynitrite used per pulse was $20 \mu \mathrm{M}$ ( $n$ $=50$ pulses). The peroxynitrite pulses were done under vortexing with a total $\mathrm{S} 1$ solution volume of $1 \mathrm{~mL}$, and the samples were pooled for assay of activity 10-15 min after the treatment with synthetic peroxynitrite. (C) Partial protection by $0.2 \mathrm{mM} \mathrm{ADP} \cdot \mathrm{V}_{1}$ against inhibition of F-actin-stimulated $\mathrm{S} 1 \mathrm{Mg}^{2+}$-ATPase activity by $2 \mathrm{~h}$ of treatment with SIN-1 $(\nabla)$. S1 was incubated with $0.2 \mathrm{mM} \mathrm{ADP} \cdot \mathrm{V}_{1}$ for $30 \mathrm{~min}$ before treatment with SIN-1, which was done as indicated for panel $\mathrm{A}$. The results for $\mathrm{S} 1$ treated with SIN-1 in the absence of $\mathrm{ADP} \cdot \mathrm{V}_{1}$ (control) are also included to allow for direct comparison $(\mathbf{)})$, and the differences were found to be statistically significant by an analysis of variance test $\left({ }^{*} p<0.001\right)$.
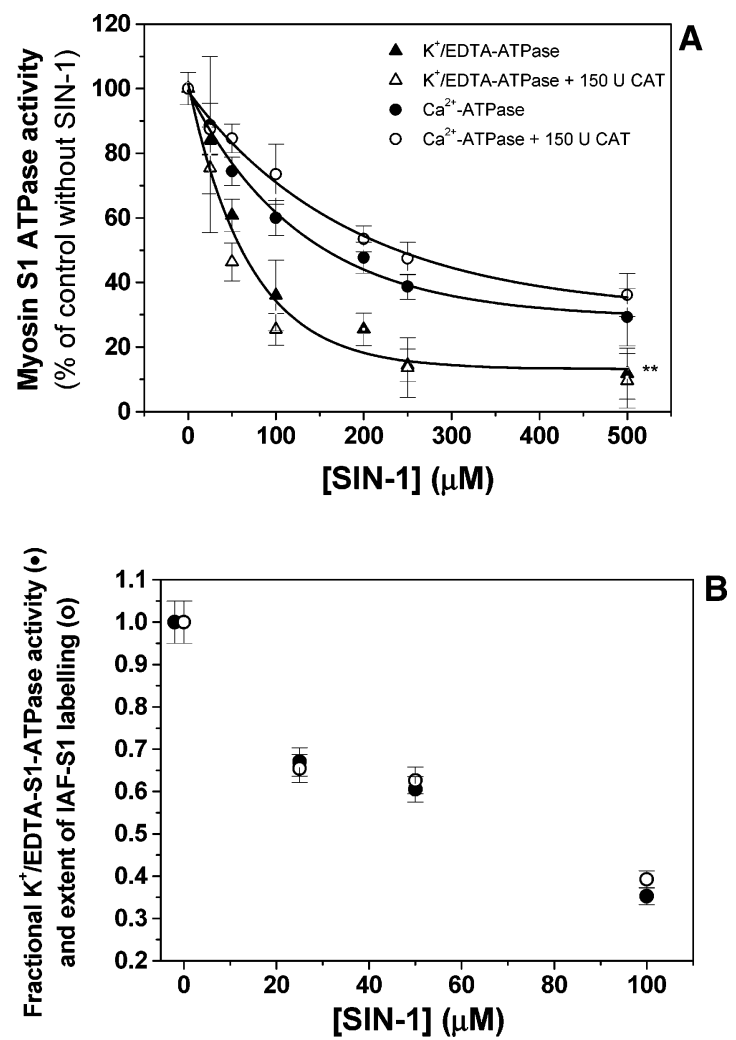

FIGURE 3: Inhibition of $\mathrm{Ca}^{2+}$ - and $\mathrm{K}^{+} /$EDTA-ATPase activities of S1 by SIN-1 (A) and the effect of treatment with SIN-1 on the IAF-labeling of S1 (B). (A) S1 $(8.7 \mu \mathrm{M})$ was treated with the concentrations of SIN-1 indicated in the abscissa in buffer, $10 \mathrm{mM}$ Tris, and $25 \mathrm{mM} \mathrm{KCl}(\mathrm{pH} 8.5)$ at $25^{\circ} \mathrm{C}(\boldsymbol{\Delta}, \boldsymbol{\bullet})$ or in this buffer supplemented with catalase $(\triangle, O)$. The circles and triangles stand for $\mathrm{Ca}^{2+}$ - and $\mathrm{K}^{+} /$EDTA-ATPase activities, respectively. The activities measured before the addition of SIN-1, $1.5 \pm 0.2$ and $3.5 \pm 0.8 \mu \mathrm{mol}$ of product $\mathrm{min}^{-1}(\mathrm{mg} \text { of } \mathrm{S} 1)^{-1}$ for $\mathrm{Ca}^{2+}$-ATPase and $\mathrm{K}^{+} /$EDTA-ATPase, respectively, were taken as $100 \%$. The difference between the inhibition of $\mathrm{K}^{+} /$EDTA-ATPase activity by SIN-1 in the absence and presence of catalase was found not to be statistically significant by an analysis of variance test $(* * p>0.05)$. (B) Fractional inhibition of $\mathrm{S} 1 \mathrm{~K}^{+} /$EDTA-ATPase (-) and fractional loss of the labeling of $\mathrm{S} 1$ at $\mathrm{Cys}_{707}$ by IAF $(\mathrm{O})$ after $2 \mathrm{~h}$ of treatment with the SIN-1 concentrations indicated in the abscissa. $\mathrm{S}_{1} \mathrm{~K}^{+} /$ EDTA-ATPase activity and IAF-S1 labeling were measured with aliquots of the same SIN-1-treated S1 samples. The data shown are the results of an experiment done in triplicate.

inhibition can be due to the reaction of SIN-1-derived peroxynitrite with amino acids located in the catalytic domain.

Cys Oxidation during Exposure of S1 to SIN-1. It has been reported that $\mathrm{S} 1$ has two highly reactive cysteines, $\mathrm{CyS}_{707}$ and $\mathrm{Cys}_{697}$, whose oxidation leads to the inhibition of F-actinstimulated $\mathrm{S} 1 \mathrm{Mg}^{2+}$-ATPase activity and also to an altered pattern of $\mathrm{Mg}^{2+}$-ATPase as well as nonphysiological $\mathrm{Ca}^{2+}$ ATPase and $\mathrm{K}^{+}$/EDTA-ATPase activities of $\mathrm{S} 1(28,45,51$, 52). Briefly, oxidation of $\mathrm{CyS}_{707}$ produces an increase of nonphysiological $\mathrm{Ca}^{2+}$-ATPase myosin activity, whereas oxidation of both reactive cysteines inhibits all of the myosinATPase activities (45). However, peroxynitrite-induced oxidation of highly reactive cysteines is one of the most established protein-chemical modifications induced by this reagent $(12,16,50)$. Figure 3A shows that exposure to SIN-1 results in inhibition of $\mathrm{K}^{+} /$EDTA-ATPase and $\mathrm{Ca}^{2+}$-ATPase activities of $\mathrm{S} 1$ with $\mathrm{IC}_{50}$ values close to that found for the inhibition of F-actin-stimulated $\mathrm{Mg}^{2+}$-ATPase activity and 
Table 1: Oxidation of S1 Cysteines by Treatment with SIN-1-Derived Peroxynitrite ${ }^{a}$

\begin{tabular}{ccc}
\hline$[\mathrm{SIN}-1](\mu \mathrm{M})$ & $\begin{array}{c}\text { very accessible Cys } \\
(\mathrm{nmol} \text { of Cys/mol of } \mathrm{S} 1)\end{array}$ & $\begin{array}{c}\text { total Cys } \\
(\mathrm{nmol} \text { of Cys/mol of S1) }\end{array}$ \\
\hline 0 & $1.96 \pm 0.41$ & $10.1 \pm 0.6$ \\
50 & $0.47 \pm 0.12$ & $6.6 \pm 0.3$ \\
100 & $0.36 \pm 0.04$ & $5.6 \pm 0.3$ \\
250 & $0.28 \pm 0.03$ & $4.0 \pm 0.2$ \\
500 & $0.09 \pm 0.05$ & $2.6 \pm 0.3$ \\
\hline
\end{tabular}

${ }^{a} \mathrm{~S} 1$ cysteines were quantified by titration of $0.5 \mathrm{mg}$ of $\mathrm{S} 1$ protein with $0.5 \mathrm{mM}$ DTNB after incubation of $\mathrm{S} 1(8.7 \mu \mathrm{M})$ for $2 \mathrm{~h}$ with the concentrations of SIN-1 listed above. Very accessible cysteines refer to the cysteines that reacted in less than $1 \mathrm{~min}$, calculated from the increase of absorbance recorded $1 \mathrm{~min}$ after DTNB addition, and the total cysteine values were determined after the samples were treated with $1 \%$ SDS (added as a solid to the solution). See Materials and Methods for further experimental details.

that $\mathrm{H}_{2} \mathrm{O}_{2}$ produced during $\mathrm{SIN}-1$ decomposition produced at most $10 \%$ inhibition of these ATPase activities, as shown by the difference of inhibition by SIN-1 in the absence and presence of catalase.

The oxidation of S1 cysteines during exposure to SIN-1 was confirmed by S1 cysteine titration with DTNB. The results obtained are listed in Table 1 and suggest that exposure to SIN-1 concentrations that produced approximately $60 \%$ inhibition of F-actin-stimulated $\mathrm{S} 1 \mathrm{Mg}^{2+}$ ATPase activity resulted in oxidation of more than $3 \mathrm{~mol}$ of cysteine/mol of S1 (treatment with $50 \mu \mathrm{M}$ SIN-1). Moreover, because $\mathrm{Cys}_{707}$ and $\mathrm{Cys}_{697}$ are highly reactive and exposed at the water/protein interface of the 3D structure of S1 (45, 53,54 ), we have also quantified the decrease in fast-reacting cysteines against DTNB upon treatment with SIN-1 (Table 1), and the results suggest that $50 \mu \mathrm{M}$ SIN-1 produced the oxidation of $1.5 \mathrm{~mol}$ of very accessible cysteines $/ \mathrm{mol}$ of $\mathrm{S} 1$. This is in good agreement with the conclusions reached on the basis of $\mathrm{Ca}^{2+}$-ATPase and $\mathrm{K}^{+} /$EDTA-ATPase activity measurements (see above). Because S1 can be selectively labeled by IAF at $\mathrm{Cys}_{707}(34,35,45)$, its oxidation by SIN-1 can also be monitored by the parallel decrease of the extent of labeling of S1 by IAF under the standard experimental conditions indicated in Materials and Methods. The results shown in Figure 3B fully confirmed this point and also demonstrated a tight correlation between the fractional decrease of the extent of labeling of $\mathrm{CyS}_{707}$ with IAF and the fractional decrease of the $\mathrm{S} 1 \mathrm{~K}^{+} /$EDTA-ATPase activity.

In addition, a more extensive cysteine oxidation is observed upon exposure to higher SIN-1 concentrations, reaching an oxidation of 7.5 of the 10 cysteines of $\mathrm{S} 1$ after treatment with $500 \mu \mathrm{M}$ SIN-1 for $2 \mathrm{~h}$.

Effect of SIN-1 on the Thermal Stability of S1. An extensive oxidation of protein cysteines can produce a large distortion of the folded native structure of a protein, eventually leading to a partially unfolded protein. This point was experimentally tested using DSC, a technique that has been shown to be very valuable for monitoring and quantifying protein conformational transitions during the proteinunfolding process $(41,55)$. To have a good signal-to-noise ratio, the DSC measurements have been done with $2.4 \mathrm{mg}$ of S1 protein/mL, a concentration 2.4-fold higher than that used for the activity measurements shown in Figure 1.

The treatment of S1 with SIN-1 largely decreased the enthalpy of unfolding of S1 (Figure 4A and Table 2) parallel to the inhibition of the F-actin-stimulated $\mathrm{S} 1 \mathrm{Mg}^{2+}$-ATPase activity at this S1 concentration (Figure 4B). The thermal unfolding of $\mathrm{S} 1$ is irreversible under the experimental conditions used in this study because a re-scan of S1 yielded a flat baseline (data not shown), a result that is in good agreement with previously reported studies on S1 thermal unfolding $(56,57)$. An analysis of the DSC data (Table 2) suggests that the unfolding conforms to a non-two-state irreversible process with only a small decrease in criticalunfolding temperature $\left(T_{\mathrm{c}}\right)$ of less than $0.4^{\circ} \mathrm{C}$, for example, after treatment of S1 with $500 \mu \mathrm{M} \mathrm{SIN-1}$ with only a small decrease in the cooperative unit, as shown by the $\Delta H_{\mathrm{v}}$ values listed in Table 2. Therefore, the DSC results suggest that the treatment with the highest SIN-1 concentrations used in this study produced a partially unfolded $\mathrm{S} 1$. This point was confirmed by the increased susceptibility to tryptic digestion of S1 treated with SIN-1 with respect to the control (untreated S1) (Figure 4C,D). Because S1 treatment with $250-500 \mu \mathrm{M}$ SIN-1 produced an extensive oxidation of $\mathrm{S} 1$ cysteines, and this can lead to a partially unfolded $\mathrm{S} 1$, we have carried out DSC scans of S1 samples treated with SIN-1 in the presence of intracellular-thiol-protecting antioxidant GSH. GSH (2 $\mathrm{mM}$ ) was found to completely protect against SIN-1induced partial unfolding of S1 (Table 2).

Binding of the ADP $\cdot \mathrm{V}_{1}$ complex upon incubation with $\mathrm{S} 1$ shifts this protein to a conformational state that simulates the intermediate catalytic state $\mathrm{S} 1 \cdot \mathrm{ADP} \cdot \mathrm{P}_{\mathrm{i}}(31,32)$, and it has been shown to largely stabilize this domain against thermal unfolding, that is, it increases the $T_{\mathrm{c}}$ value nearly $10{ }^{\circ} \mathrm{C}(57,58)$. Because the treatment with SIN-1 produced the oxidation of highly reactive cysteines that are located in the catalytic domain close to the catalytic center of S1 (see above), we considered the possibility that the distortion of the catalytic site induced by treatment with SIN-1 could lead to the impairment of the ability of S1 to reach the intermediate state $\mathrm{S} 1 \cdot \mathrm{ADP} \cdot \mathrm{P}_{\mathrm{i}}$. The results shown in Figure $4 \mathrm{E}$ demonstrate that this is indeed the case, as treatment for $2 \mathrm{~h}$ with $500 \mu \mathrm{M}$ SIN-1 decreased the ratio between the enthalpies of the peaks of $T_{\mathrm{c}}$ of $57 \pm 0.5$ and $49 \pm 1{ }^{\circ} \mathrm{C}$ from $3.3 \pm 0.1$ to $0.50 \pm 0.05$. This effect of SIN-1 is not produced by decomposed SIN-1 (results not shown), suggesting that it is not due to long-lived products generated during SIN-1 decomposition. Therefore, these results indicate that treatment of S1 with SIN-1 results in a large decrease of the conformational flexibility of the catalytic domain of S1.

Protein Carbonyl and 3-Nitrotyrosine Formation during Exposure of S1 to SIN-1. In addition to cysteine oxidation, treatment of proteins with peroxynitrite can also produce protein carbonyls and 3-nitrotyrosine formation $(9,14,59)$. Therefore, the possibility that these modifications can be underlying the functional impairment of S1 observed after treatment with SIN-1 deserves to be studied.

The results of the measurements of protein carbonyls in S1 before and after treatment with SIN-1 leading to an inhibition close to $90 \%$ of the F-actin-stimulated S1 $\mathrm{Mg}^{2+}$ ATPase activity are shown in Figure 5A and allowed us to conclude that the increase of $\mathrm{S} 1$ protein carbonyls elicited by treatment with SIN-1 is lower than $0.1 \mathrm{nmol}$ of protein carbonyls/mol of S1. Therefore, protein carbonyl formation is unlikely to play a significant role in the inhibition of F-actin-stimulated $\mathrm{S} 1 \mathrm{Mg}^{2+}$-ATPase activity and in the 


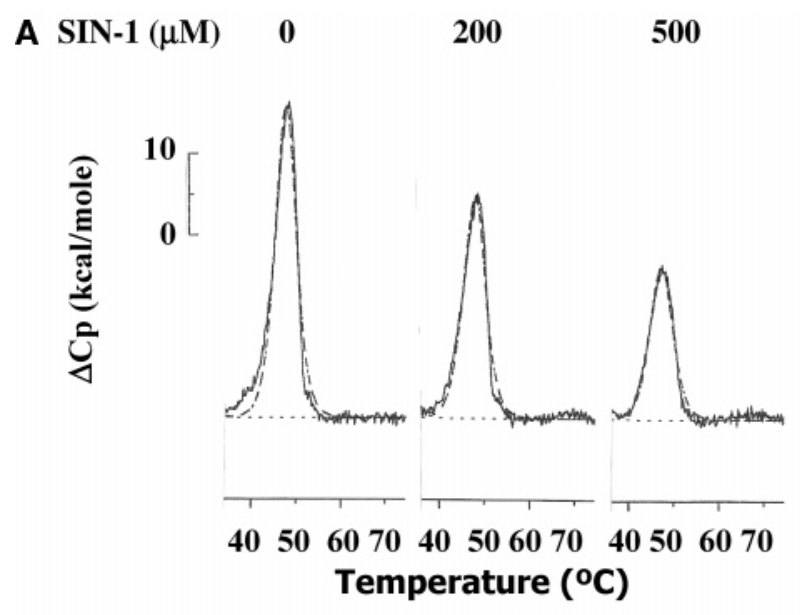

B

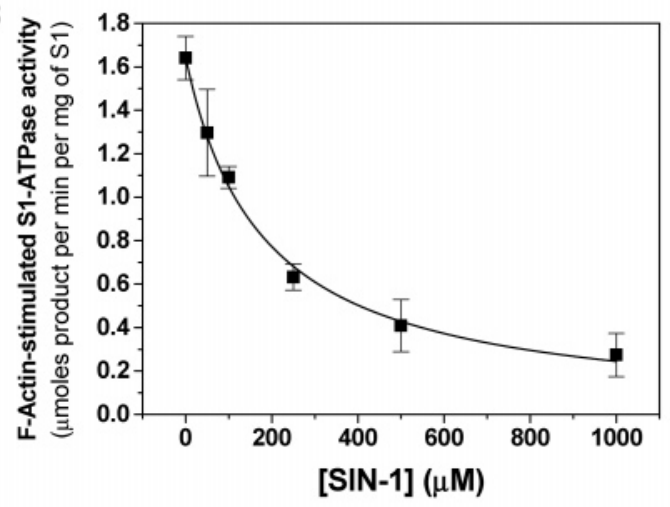

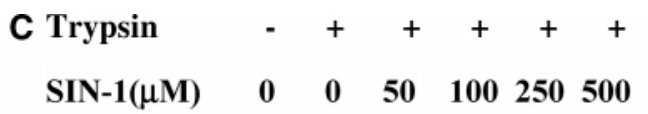

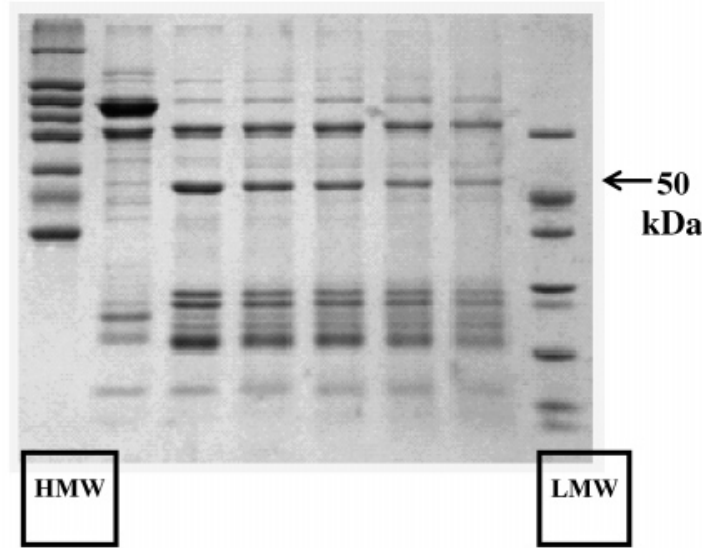

D

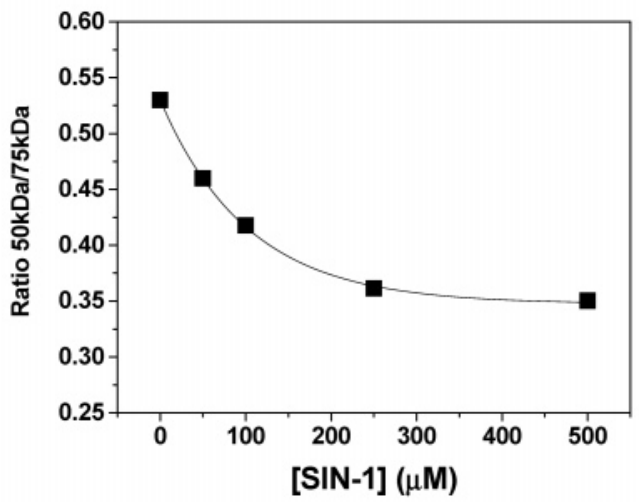

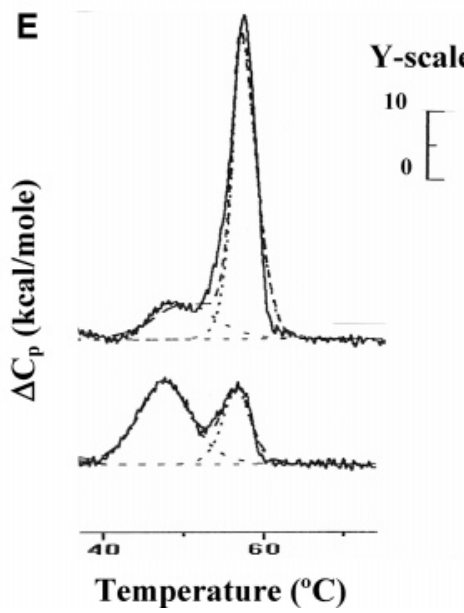

a) $\mathrm{S} 1+0.2 \mathrm{mM} \mathrm{ADP} \cdot \mathrm{V}$

$\mathrm{T}_{\mathrm{c}}($ Peak I $)=49.8^{\circ} \mathrm{C}$

$\mathrm{T}_{\mathrm{c}}($ Peak II $)=\mathbf{5 7 . 5}^{\circ} \mathrm{C}$

Ratio $\left(\Delta H_{I I} / \Delta H_{I}\right)=3.3 \pm 0.1$

b) $(\mathrm{S} 1+500$ uM SIN-1) +0.2 mM ADP.V

$T_{c}($ Peak I $)=47.5^{\circ} \mathrm{C}$

$\mathrm{T}_{\mathrm{c}}($ Peak II $)=56.5^{\circ} \mathrm{C}$

Ratio $\left(\Delta H_{I I} / \Delta H_{I}\right)=0.5 \pm 0.05$

FIGURE 4: Effect of the treatment of S1 with SIN-1 on the thermal unfolding of S1 and the ability of ADP. $\mathrm{V}_{1}$ to shift $\mathrm{S} 1$ to the intermediate conformational state $\mathrm{M}^{* *} \cdot \mathrm{ADP} \cdot \mathrm{P}_{\mathrm{i}}$. (A) Representative DSC traces of $\mathrm{S} 1(21 \mu \mathrm{M})$ treated with indicated SIN- 1 concentrations for $2 \mathrm{~h}$ in buffer, $10 \mathrm{mM}$ Tris, and $25 \mathrm{mM} \mathrm{KCl}(\mathrm{pH} 8.5)$ at $25^{\circ} \mathrm{C}$. (The buffer is described in the legend for Figure 1A.) To minimize the pH change during the temperature scan after the treatment with SIN-1, the samples were placed in the DSC buffer indicated in Materials and Methods, and the scans were performed at a rate of $60^{\circ} \mathrm{C} / \mathrm{h}$. (B) Inhibition of the F-actin-stimulated $\mathrm{Mg}^{2+}$-ATPase activity of $21 \mu \mathrm{M} \mathrm{S1}$ by SIN-1 after $2 \mathrm{~h}$ of treatment with the SIN-1 concentrations indicated in the abscissa using the experimental conditions indicated for the data shown in panel A. (C) Coomassie blue stained SDS-PAGE of partially digested S1 before and after treatment with SIN-1. S1 (8.7 $\mu$ M) was treated with the indicated SIN-1 concentrations for $2 \mathrm{~h}$ in buffer, $10 \mathrm{mM}$ Tris, and $25 \mathrm{mM} \mathrm{KCl}(\mathrm{pH} 8.5)$ at $25^{\circ} \mathrm{C}$ and, thereafter, partially digested with trypsin (molar ratio of 1:50 relative to S1) for 30 min. SDS-PAGE was performed in $12 \%$ polyacrylamide gels with $10 \mu \mathrm{g}$ of S1 protein loaded per lane, and the molecular weight markers were loaded in the left and right lanes labeled with HMW and LMW (high and low molecular weight markers), respectively. (D) The ratio between the intensities of the bands of 50 and 75 (ratio 50/75) is plotted as a function of SIN-1 concentration. (E) Representative DSC traces of S1 $(21 \mu \mathrm{M})$ in a DSC buffer supplemented with $0.2 \mathrm{mM} \mathrm{Mg}^{2+}$ $\mathrm{ADP} \cdot \mathrm{V}_{1}$ and incubated for $30 \mathrm{~min}$ before starting the scan. (a) Control, not treated with SIN-1, and (b) S1 treated with $500 \mu \mathrm{M}$ SIN-1 for $2 \mathrm{~h}$ in the buffer indicated for panel A. Dotted lines are the best fits to a two-peak non-two-state transitions obtained with MicroCal Origin software.

impaired conformational response to $\mathrm{ADP} \cdot \mathrm{V}_{1}$ of $\mathrm{SIN}-1-$ treated S1.
Nitrotyrosine formation after the treatment of S1 with SIN-1 was detected and quantified (Figure 5B), although the 
Table 2: Effect of Treatment with SIN-1 on the Thermal Unfolding of S1 ${ }^{a}$

\begin{tabular}{|c|c|c|c|}
\hline sample & $\begin{array}{c}T_{\mathrm{c}} \\
\left({ }^{\circ} \mathrm{C}\right)\end{array}$ & $\begin{array}{c}\Delta H \\
(\mathrm{kcal} / \mathrm{mol} \text { of } \mathrm{S} 1)\end{array}$ & $\begin{array}{c}\Delta H_{\mathrm{v}} \\
(\mathrm{kcal} / \mathrm{mol} \text { of } \mathrm{S} 1)\end{array}$ \\
\hline $\mathrm{S} 1$ (control) $^{b}$ & $47.6 \pm 0.1$ & $245 \pm 6$ & $131 \pm 2$ \\
\hline $\mathrm{S} 1+200 \mu \mathrm{M}$ SIN-1 & $47.4 \pm 0.1$ & $189 \pm 9$ & $123 \pm 2$ \\
\hline $\mathrm{S} 1+500 \mu \mathrm{M}$ SIN-1 & $47.2 \pm 0.1$ & $136 \pm 10$ & $124 \pm 2$ \\
\hline $\mathrm{S} 1+2 \mathrm{mM} \mathrm{GSH}$ & $47.6 \pm 0.1$ & $235 \pm 8$ & $149 \pm 2$ \\
\hline $\mathrm{S} 1+2 \mathrm{mM} \mathrm{GSH}+500 \mu \mathrm{M} \mathrm{SIN}-1$ & $47.7 \pm 0.1$ & $210 \pm 6$ & $146 \pm 2$ \\
\hline
\end{tabular}

${ }^{a} \mathrm{~S} 1(21 \mu \mathrm{M})$ was treated with the listed concentrations of SIN-1 for $2 \mathrm{~h}$ in the absence and presence of $2 \mathrm{mM}$ GSH before being loaded into the calorimeter. DSC data were fit to a non-two-state transition with the Origin software of the MicroCal MC2 differential scanning calorimeter, which yielded $T_{\mathrm{c}}$, the critical temperature of unfolding; $\Delta H$, the enthalpy of unfolding; and $\Delta H_{\mathrm{v}}$, the van't Hoff enthalpy that can be taken as an index of the cooperativity of unfolding for slow, irreversible unfolding processes (55). Further experimental details are given in Materials and Methods. ${ }^{b}$ The same results were obtained with S1 treated with the addition of $500 \mu \mathrm{M}$ decomposed SIN-1.
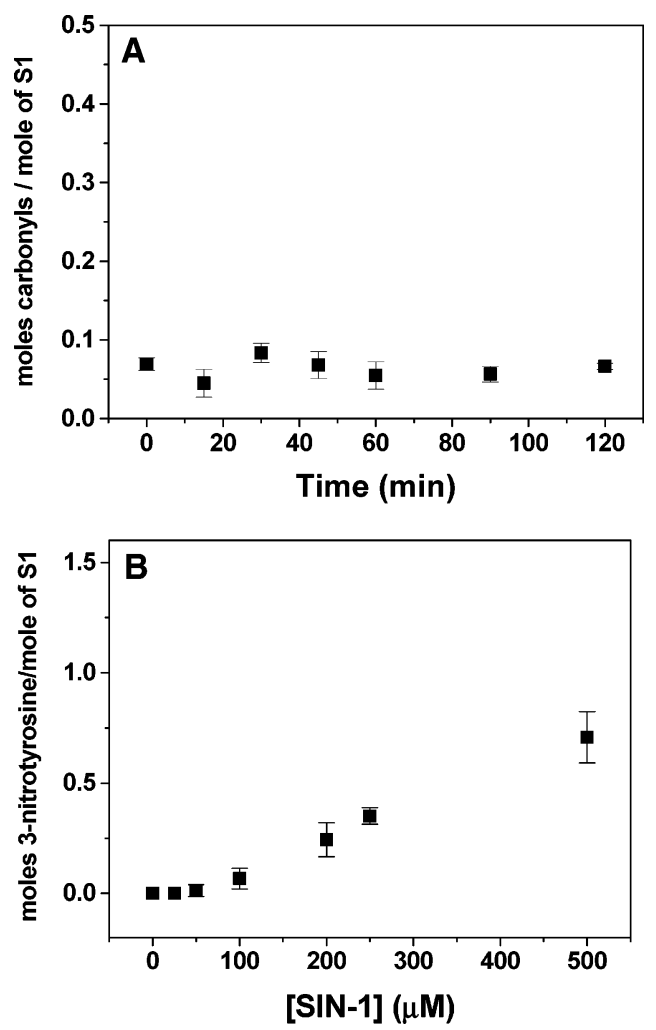

FIGURE 5: Protein carbonyl and 3-nitrotyrosine formation during the treatment of S1 with SIN-1. (A) Protein carbonyls as a function of the time of treatment of $\mathrm{S} 1(8.7 \mu \mathrm{M})$ with $100 \mu \mathrm{M}$ SIN-1 in buffer, $10 \mathrm{mM}$ Tris, and $25 \mathrm{mM} \mathrm{KCl}(\mathrm{pH} 8.5)$ at $25^{\circ} \mathrm{C}$. The proteins carbonyls were measured as indicated in Materials and Methods. (B) 3-Nitrotyrosine formation after treatment for $2 \mathrm{~h}$ with the SIN-1 concentrations indicated in the abscissa of $\mathrm{S} 1(8.7 \mu \mathrm{M})$ in buffer, $10 \mathrm{mM}$ Tris, and $25 \mathrm{mM} \mathrm{KCl}(\mathrm{pH} 8.5)$ at $25^{\circ} \mathrm{C}$. The concentration of 3-nitrotyrosines was measured as indicated in Materials and Methods.

level of nitrotyrosines in S1 is lower than 0.05 mol of 3-nitrotyrosine/mol of S1 after treatment for $2 \mathrm{~h}$ with $50 \mu \mathrm{M}$ SIN-1, which resulted in a 50-60\% loss of F-actin-stimulated $\mathrm{S} 1 \mathrm{Mg}^{2+}$-ATPase activity. Furthermore, after $2 \mathrm{~h}$ of treatment with $500 \mu \mathrm{M}$ SIN-1, which resulted in more than a $90 \%$ loss of F-actin-stimulated S1 $\mathrm{Mg}^{2+}$-ATPase activity, only $0.7 \mathrm{~mol}$ of nitrotyrosine/mol of $\mathrm{S} 1$ is produced. Therefore, these results only support at most a marginal role of nitrotyrosine formation in the inhibition of F-actin-stimulated $\mathrm{S} 1 \mathrm{Mg}^{2+}$-ATPase activity during treatment of S1.

Despite the low level of 3-nitrotyrosine formation, we decided to monitor the protein domain in which this oxidative protein modification takes place to critically evaluate the possibility of its implication in the blockage by SIN-1 treatment against the $\mathrm{ADP} \cdot \mathrm{V}_{1}$-induced conformational shift. It has been shown that mild tryptic digestion of S1 leads to a specific protein fragmentation that allows the resolving of each of the major functional protein domains of S1 in SDSPAGE $(54,60)$. Thus, tryptic S1 fragments were analyzed by Western blot to detect 3-nitrotyrosine formation in S1 treated with chemically synthesized $\mathrm{ONOO}^{-}$and its tryptic fragments. The results (not shown) indicate that 3-nitrotyrosines appear to be located in the $25 \mathrm{kDa}$ tryptic fragment, one of the catalytic domain-derived protein fragments that contains several tyrosines $(53,54)$.

Protection by the Antioxidants GSH, NADH, and Ascorbate against Inhibition by SIN-1 of F-Actin-Stimulated S1 $\mathrm{Mg}^{2+}$-ATPase Activity. Figure 6 shows that major antioxidants present in normal muscle cells protect against the inhibition of F-actin-stimulated $\mathrm{S} 1 \mathrm{Mg}^{2+}$-ATPase activity by SIN-1-derived peroxynitrite. Significant protection can be attained with $100 \mu \mathrm{M}$ GSH or ascorbate, whereas NADH affords only approximately $50 \%$ protection. In addition, GSH and ascorbate have similar high efficiencies as protecting agents because their concentrations that produce half protection $\left(\mathrm{IC}_{50}\right)$ are close to the concentration of SIN-1 $(50 \mu \mathrm{M})$. Because the redox chemistry of ascorbate with reactive oxygen species (like the superoxide anion) is complex, owing to the formation of the ascorbate free radical (61), to exclude the possibility that in this case the protection could be due to interference with peroxynitrite formation during SIN-1 decomposition rather than to real protection against peroxynitrite, we have also studied the dependence on ascorbate concentration of the inhibition of the F-actin-stimulated S1 $\mathrm{Mg}^{2+}$-ATPase activity by one pulse of $500 \mu \mathrm{M}$ synthetic peroxynitrite. The results are shown in Figure 6B and indicate that ascorbate significantly protects against the inhibition of $\mathrm{S} 1$ by peroxynitrite, with an $\mathrm{IC}_{50}$ value of $100 \mu \mathrm{M}$.

\section{DISCUSSION}

Exposure of S1 to SIN-1 produced a time-dependent inhibition of F-actin-stimulated S1 ATPase activity that correlated with the kinetics of peroxynitrite generation upon SIN-1 decomposition. The following experimental observations demonstrated that peroxynitrite was the agent causing this inhibition: (1) blockage of inhibition upon exposure to SIN-1 by SOD + catalase but not by catalase alone; (2) the lack of an effect of incubation with decomposed SIN-1; and (3) inhibition by treatment with micromolar pulses of chemically synthesized peroxynitrite. The obtained $\mathrm{IC}_{50}$ value for the inhibition by SIN-1 was $46.7 \pm 8.3 \mu \mathrm{M}$ SIN-1 with $8.7 \mu \mathrm{M} \mathrm{S} 1$ and $120 \pm 10 \mu \mathrm{M}$ SIN-1 with $21 \mu \mathrm{M} \mathrm{S} 1$, that is, 

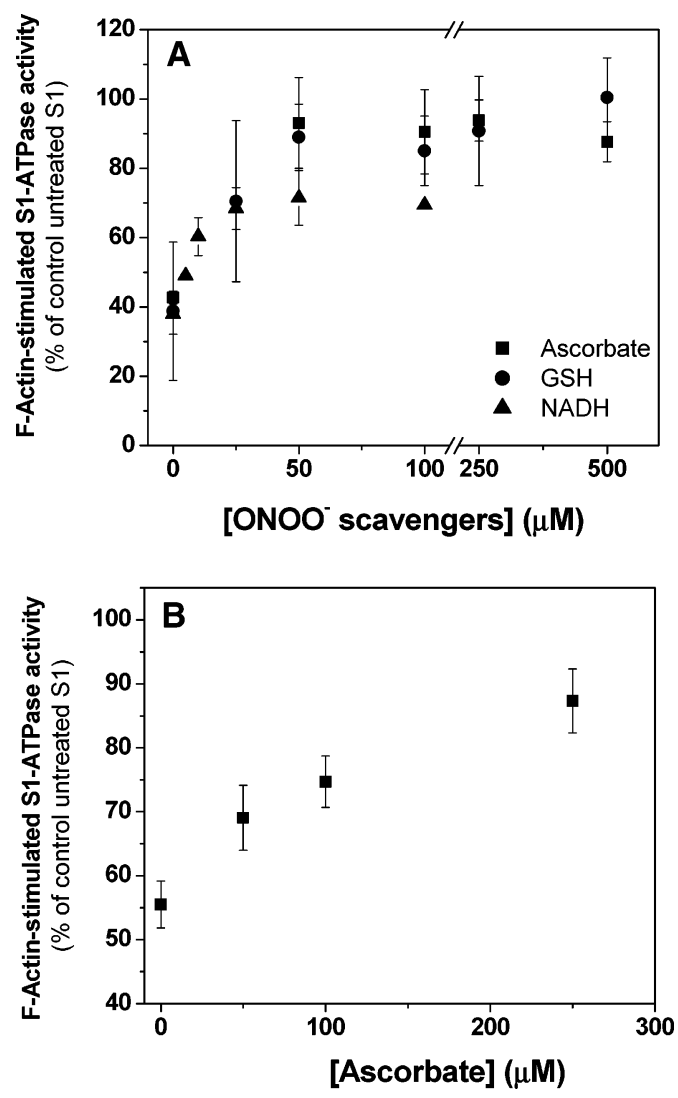

FIGURE 6: Protection by GSH, ascorbate, and NADH against inhibition of S1 by SIN-1 and synthetic peroxynitrite. (A) Protection against the inhibition of F-actin-stimulated $\mathrm{S} 1 \mathrm{Mg}^{2+}$-ATPase activity by $50 \mu \mathrm{M}$ SIN-1 by GSH $(\bullet)$, NADH $(\mathbf{\Delta})$, and ascorbate $(\boldsymbol{\square})$. The samples were assayed for activity after $2 \mathrm{~h}$ of incubation of $\mathrm{S} 1$ $(8.7 \mu \mathrm{M})$ with $50 \mu \mathrm{M} \mathrm{SIN}-1$ at $25^{\circ} \mathrm{C}$ in buffer, $10 \mathrm{mM}$ Tris, and $25 \mathrm{mM} \mathrm{KCl}(\mathrm{pH} 8.5)$ supplemented with the concentrations of the antioxidants (GSH, NADH, or ascorbate) indicated in the abscissa. (B) Protection by ascorbate against the inhibition of F-actinstimulated $\mathrm{S} 1 \mathrm{Mg}^{2+}$-ATPase activity by one pulse of $500 \mu \mathrm{M}$ synthetic peroxynitrite. Synthetic peroxynitrite was added to S1 (8.7 $\mu \mathrm{M}$ ) in buffer, $0.5 \mathrm{M}$ Tris, and $25 \mathrm{mM} \mathrm{KCl} \mathrm{(pH} \mathrm{7.2)} \mathrm{under} \mathrm{vortex}$ at room temperature. The samples were pooled for assay of activity 10-15 min after treatment with synthetic peroxynitrite.

$50 \%$ inhibition with a SIN-1/S1 molar ratio close to 5.5. Because the generation of peroxynitrite from SIN-1 decomposition is a slow process $(22,25)$, showing a half-time of $42 \pm 2 \mathrm{~min}$ in our experimental conditions, with a peak of peroxynitrite concentration reaching approximately $1 \%$ of total SIN-1 due to the short life of peroxynitrite in solutions at $\mathrm{pH} 7-7.4$ (see Figure 1 and Martín-Romero et al. (25)), we concluded that an exposure of $2 \mathrm{~h}$ to submicromolar fluxes of peroxynitrite (peak flux below $1 \mu \mathrm{M} / \mathrm{min}$ ) is sufficient to produce $50 \%$ inhibition of F-actin-stimulated $\mathrm{S} 1 \mathrm{Mg}^{2+}$-ATPase activity. Recall that submicromolar concentrations of peroxynitrite have been reportedly reached in tissues during the ischemia/reperfusion syndrome and inflammation $(8,26)$, where the duration of the tissue insult lasts from $30 \mathrm{~min}$ to several hours. Moreover, myosin and creatine kinase are muscle proteins showing higher nitrotyrosine content, a peroxynitrite fingerprint marker in cells and tissues, after ischemia/reperfusion episodes or in aged muscle $(1,6,10)$. This is consistent with the high concentration of myosin in the sarcoplasm of muscle cells and with the fact that the $\mathrm{IC}_{50}$ value for inhibition of F-actin-stimulated S1 $\mathrm{Mg}^{2+}$-ATPase activity by SIN-1 and/or synthetic per- oxynitrite reported in this article is close to that reported for the inhibition of creatine kinase (62) and nearly 4-fold lower than the one reported for another abundant muscle protein, the sarcoplasmic reticulum $\mathrm{Ca}^{2+} \mathrm{Mg}^{2+}$-ATPase $(15,16,50)$.

Our results show that three of the major antioxidants present in muscle cells (GSH, ascorbate, and NADH) can significantly protect against $\mathrm{S} 1$ inhibition by the peroxynitrite-releasing agent $\mathrm{SIN}-1$ with an $\mathrm{IC}_{50} / \mathrm{SIN}-1$ ratio close to 1 for all of them ( $\mathrm{IC}_{50}$ approximately $50 \mu \mathrm{M}$ for $50 \mu \mathrm{M}$ SIN-1), although NADH only affords nearly $50 \%$ protection. These results suggest that in normal physiological conditions the sarcoplasm concentrations of these antioxidants are high enough, 5-10 mM GSH, $\geq 0.5 \mathrm{mM}$ ascorbate, (63) and $\geq 100 \mu \mathrm{M}$ (NADH $+\mathrm{NADPH})$ (64), to ensure proper protection against an acute and short-lived peroxynitrite insult. However, the increase in the 3-nitrotyrosine content of myocardial myosin after ischemia/reperfusion $(1,6)$ indicates that these antioxidant defenses are largely depleted near myofibrils during acute oxidative insults, suggesting that myofibrils are very close to the subcellular sites of peroxynitrite generation. This is indeed the case, as the well-known sources of superoxide anion are the redox chains of the mitochondria and plasma membrane $(38,65,66)$.

Although 3-nitrotyrosine formation can be detected in S1 treated with SIN-1 or synthetic peroxynitrite, the extent of this chemical modification of S1 was found to be too low to account for the inhibition of F-actin-stimulated $\mathrm{S} 1 \mathrm{Mg}^{2+}$ ATPase activity, that is, less than $0.05 \mathrm{~mol}$ of 3-nitrotyrosine/ mol of S1, when $50 \%$ of the activity is lost. The failure of bicarbonate to enhance the inhibition of F-actin-stimulated $\mathrm{S} 1 \mathrm{Mg}^{2+}$-ATPase activity by SIN-1 or synthetic peroxynitrite is also fully consistent with this conclusion because bicarbonate enhances 3-nitrotyrosine formation by peroxynitrite via a radical pathway involving tyrosyl radical formation after the attack of $\mathrm{CO}_{3}{ }^{-}$(7-9). Furthermore, the formation of protein carbonyls is barely detectable during the treatment of S1 with SIN-1 concentrations producing more than $90 \%$ inhibition of F-actin-stimulated S1 $\mathrm{Mg}^{2+}$-ATPase activity (less than $0.1 \mathrm{~mol}$ of protein carbonyl/mol of S1). However, fast-reacting cysteines against DTNB per mole of S1 are largely oxidized ( 1.5 over 2 , i.e., $75 \%$ ) during treatments with SIN-1 producing $60 \%$ inhibition of S1 ATPase activities, and it has been shown that oxidation or chemical modification of the two highly reactive cysteines of S1, $\mathrm{Cys}_{707}$ and $\mathrm{Cys}_{697}$, results in strong inhibition of the S1 ATPase activities $(28,45,51,52)$. This point was confirmed by the tight correlation between the fractional decrease of the extent of labeling of $\mathrm{CyS}_{707}$ with IAF and the fractional decrease of S1 ATPase activity after exposure to SIN-1 reported in this article, as ascertained by $\mathrm{S} 1 \mathrm{Cys}_{707}$ titration with IAF under well-established experimental conditions (34, $35,45)$. These cysteines are located in the catalytic domain of $\mathrm{S} 1$, very close to each other in the 3D structure of a domain that undergoes significant conformational changes during the catalytic cycle $(53,54)$, and the DSC results reported in this article showed that SIN-1-treated S1 has a largely impaired ability to attain the conformation of the obligatory intermediate catalytic state $\mathrm{S} 1 \cdot \mathrm{Mg}^{2+}-\mathrm{ADP} \cdot \mathrm{P}_{\mathrm{i}}$, which in nontreated $\mathrm{S} 1$ is induced upon incubation with $\mathrm{Mg}^{2+}-\mathrm{ADP} \cdot \mathrm{V}_{1}(31,32)$. Consistent with this result $\mathrm{Mg}^{2+}$ $\mathrm{ADP} \cdot \mathrm{V}_{1}$ was found to afford partial protection against the 
inhibition of $\mathrm{S} 1$ by peroxynitrite. Therefore, the oxidation of $\mathrm{Cys}_{707}$ and $\mathrm{Cys}_{697}$ can account for the inhibition of F-actinstimulated $\mathrm{S} 1 \mathrm{Mg}^{2+}$-ATPase activity by peroxynitrite through the blockage of the shift of the catalytic center to reach the conformation attained in the intermediate $\mathrm{S} 1 \cdot \mathrm{Mg}^{2+}-\mathrm{ADP} \cdot \mathrm{P}_{\mathrm{i}}$ state required for the progress of the catalytic cycle. In conclusion, $\mathrm{S} 1$ is inhibited by peroxynitrite acting as a strong oxidant, whereas peroxynitrite-derived radicals play only a secondary role in this inhibition.

Interestingly, treatment of S1 with SIN-1 concentrations producing peroxynitrite fluxes close to or higher than $1 \mu \mathrm{M}$ / min (e.g., $\geq 100 \mu \mathrm{M} \mathrm{SIN-1)}$ resulted in an extensive oxidation of $\mathrm{S} 1$ cysteines and a partial S1 unfolding at physiological temperatures, as monitored by the decrease of the enthalpy of unfolding measured in DSC experiments and the increased sensitivity to tryptic digestion of SIN-1-treated S1. The full protection afforded by $2 \mathrm{mM}$ GSH against peroxynitriteinduced S1 unfolding suggests a major role for cysteine oxidation in protein structural alterations leading to the oxidative unfolding of $\mathrm{S} 1$. In addition, this oxidative unfolding must lead to a partially unfolded S1 state that does not rapidly evolve toward a completely unfolded protein because the activity remaining after treatment of S1 with SIN-1 is steady for at least $1 \mathrm{~h}$. Because the ability of F-actin to stimulate $\mathrm{S} 1 \mathrm{Mg}^{2+}$-ATPase is lost after the treatment of S1 with SIN-1 and the highly reactive cysteines, $\mathrm{Cys}_{707}$ and $\mathrm{Cys}_{697}$, are close to the active site binding domain in S1, the simplest hypothesis is that this domain undergoes an oxidative unfolding linked to cysteine oxidation. These peroxynitrite fluxes can be attained in vivo during inflammation $(8,26)$, and an acute exposure of myosin to these peroxynitrite fluxes may produce an oxidation-induced irreversible myosin partial unfolding in cells and tissues. Because unfolded, oxidized proteins can be rapidly degraded by the intracellular proteasome $(67,68)$ and peroxynitrite increases the degradation of several cellular proteins by the proteasome (69), taking into account the high concentration of myosin in muscle cells could explain the significant loss in myofibrillar mass. To the best of our knowledge, this is the first report of a peroxynitrite-induced oxidative protein unfolding case, a phenomenon that can allow the rationalization of the rapid loss of muscle mass after inflammation or ischemic insults on simple biochemical grounds.

\section{REFERENCES}

1. Mihm, M. J., Yu, F., Carnes, C. A., Reiser, P. J., McCarthy, P. M., Van Wagoner, D. R., and Bauer, J. A. (2001) Impaired myofibrillar energetics and oxidative injury during human atrial fibrillation, Circulation 104, 174-180.

2. Canton, M., Neverova, I., Menabo, R., Van Eyk, J., and Di Lisa, F. (2004) Evidence of myofibrillar protein oxidation induced by postischemic reperfusion in isolated rat hearts, Am. J. Physiol. 286, H870-H877.

3. Nagasawa, T., Hatayama, T., Watanabe, Y., Tanaka, M., Niisato, Y., and Kitts, D. D. (1997) Free radical-mediated effects on skeletal muscle protein in rats treated with $\mathrm{Fe}$-nitrilotriacetate, Biochem. Biophys. Res. Commun. 231, 37-41.

4. Andrade, F. H., Reid, M. B., and Westerblad, H. (2001) Contractile response of skeletal muscle to low peroxide concentrations: myofibrillar calcium sensitivity as a likely target for redoxmodulation, FASEB J. 15, 309-311.

5. Eliasson, M. J., Huang, Z., Ferrante, R. J., Sasamata, M., Molliver, M. E., Snyder, S. H., and Moskowitz, M. A. (1999) Neuronal nitric oxide synthase activation and peroxynitrite formation in ischemic stroke linked to neural damage, J. Neurosci. 19, 59105918.
6. Mihm, M. J., Yu, F., Reiser, P. J., and Bauer, J. A. (2003) Effects of peroxynitrite on isolated cardiac trabeculae: selective impact on myofibrillar energetic controllers, Biochimie 85, 587-596.

7. Ischiropoulos, H., Zhu, L., Chen, J., Tsai, M., Martin, J. C., Smith, C. D., and Beckman, J. S. (1992) Peroxynitrite-mediated tyrosine nitration catalyzed by superoxide dismutase, Arch. Biochem. Biophys. 298, 431-437.

8. Murphy, M. P., Packer, M. A., Scarlett, J. L., and Martin, S. W. (1998) Peroxynitrite: a biologically significant oxidant, Gen. Pharmacol. 31, 179-186.

9. Radi, R. (2004) Nitric oxide, oxidants, and protein tyrosine nitration, Proc. Natl. Acad. Sci. U.S.A. 101, 4003-4008.

10. Kanski, J., Hong, S. J., and Schoneich, C. (2005) Proteomic analysis of protein nitration in aging skeletal muscle and identification of nitrotyrosine-containing sequences in vivo by nanoelectrospray ionization tandem mass spectrometry, J. Biol. Chem. 280, 24261-24266.

11. Koppenol, W. H., Moreno, J. J., Pryor, W. A., Ischiropoulos, H., and Beckman, J. S. (1992) Peroxynitrite, a cloaked oxidant formed by nitric oxide and superoxide, Chem. Res. Toxicol. 5, 834-842.

12. Radi, R., Beckman, J. S., Bush, K. M., and Freeman, B. A. (1991) Peroxynitrite oxidation of sulfhydryls. The cytotoxic potential of superoxide and nitric oxide, J. Biol. Chem. 266, 4244-4250.

13. Quijano, C., Alvarez, B., Gatti, R. M., Augusto, O., and Radi, R. (1997) Pathways of peroxynitrite oxidation of thiol groups, Biochem. J. 322, 167-173.

14. Ischiropoulos, H., and al-Mehdi, A. B. (1995) Peroxynitritemediated oxidative protein modifications, FEBS Lett. 364, 279282.

15. Viner, R. I., Huhmer, A. F., Bigelow, D. J., and Schoneich, C. (1996) The oxidative inactivation of sarcoplasmic reticulum $\mathrm{Ca}^{2+}$ ATPase by peroxynitrite, Free Radical Res. 24, 243-259.

16. Viner, R. I., Williams, T. D., and Schoneich, C. (1999) Peroxynitrite modification of protein thiols: oxidation, nitrosylation, and S-glutathiolation of functionally important cysteine residue(s) in the sarcoplasmic reticulum Ca-ATPase, Biochemistry 38, 1240812415.

17. Denicola, A., Freeman, B. A., Trujillo, M., and Radi, R. (1996) Peroxynitrite reaction with carbon dioxide/bicarbonate: kinetics and influence on peroxynitrite-mediated oxidations, Arch. Biochem. Biophys. 333, 49-58.

18. Squadrito, G. L., and Pryor, W. A. (1998) Oxidative chemistry of nitric oxide: the roles of superoxide, peroxynitrite, and carbon dioxide, Free Radical Biol. Med. 25, 392-403.

19. Uppu, R. M., and Pryor, W. A. (1996) Synthesis of peroxynitrite in a two-phase system using isoamyl nitrite and hydrogen peroxide, Anal. Biochem. 236, 242-249.

20. Trackey, J. L., Uliasz, T. F., and Hewett, S. J. (2001) SIN-1induced cytotoxicity in mixed cortical cell culture: peroxynitritedependent and -independent induction of excitotoxic cell death, J. Neurochem. 79, 445-455.

21. Gutierrez-Martin, Y., Martin-Romero, F. J., Henao, F., and Gutierrez-Merino, C. (2005) Alteration of cytosolic free calcium homeostasis by SIN-1: high sensitivity of L-type $\mathrm{Ca}^{2+}$ channels to extracellular oxidative/nitrosative stress in cerebellar granule cells, J. Neurochem. 92, 973-989.

22. Kelm, M., Dahmann, R., Wink, D., and Feelisch, M. (1997) The nitric oxide/superoxide assay. Insights into the biological chemistry of the NO/O-2 interaction, J. Biol. Chem. 272, 9922-9932.

23. Huie, R. E., and Padmaja, S. (1993) The reaction of NO with superoxide. Free Radical Res. Commun. 18, 195-199.

24. Radi, R. (1998) Peroxynitrite reactions and diffusion in biology, Chem. Res. Toxicol. 11, 720-721.

25. Martin-Romero, F. J., Gutierrez-Martin, Y., Henao, F., and Gutierrez-Merino, C. (2004) Fluorescence measurements of steady-state peroxynitrite production upon SIN-1 decomposition: NADH versus dihydrodichlorofluorescein and dihydrorhodamine 123, J. Fluoresc. 14, 17-23.

26. Bao, F., and Liu, D. (2002) Peroxynitrite generated in the rat spinal cord induces neuron death and neurological deficits, Neuroscience $115,839-849$.

27. Weeds, A. G., and Taylor, R. S. (1975) Separation of subfragment-1 isoenzymes from rabbit skeletal muscle myosin, Nature 257, 54-56.

28. Margossian, S. S., and Lowey, S. (1982) Preparation of myosin and its subfragments from rabbit skeletal muscle, Methods Enzymol. 85, 55-71. 
29. Toyoshima, Y. Y., Kron, S. J., McNally, E. M., Niebling, K. R., Toyoshima, C., and Spudich, J. A. (1987) Myosin subfragment-1 is sufficient to move actin filaments in vitro, Nature $328,536-$ 539.

30. Goodno, C. C. (1979) Inhibition of myosin ATPase by vanadate ion, Proc. Natl. Acad. Sci. U.S.A. 76, 2620-2624.

31. Smith, C. A., and Rayment, I. (1996) X-ray structure of the magnesium(II).ADP.vanadate complex of the Dictyostelium discoideum myosin motor domain to 1.9 A resolution, Biochemistry $35,5404-5417$.

32. Werber, M. M., Peyser, Y. M., and Muhlrad, A. (1992) Characterization of stable beryllium fluoride, aluminum fluoride, and vanadate containing myosin subfragment 1-nucleotide complexes, Biochemistry 31, 7190-7197.

33. Peyser, Y. M., Ben-Hur, M., Werber, M. M., and Muhlrad, A. (1996) Effect of divalent cations on the formation and stability of myosin subfragment 1-ADP-phosphate analogue complexes, Biochemistry 35, 4409-4416.

34. Phan, B. C., Peyser, Y. M., Reisler, E., and Muhlrad, A. (1997) Effect of complexes of ADP and phosphate analogs on the conformation of the Cys707-Cys697 region of myosin subfragment 1, Eur. J. Biochem. 243, 636-642.

35. Tiago, T., Aureliano, M., and Gutierrez-Merino, C. (2004) Decavanadate binding to a high affinity site near the myosin catalytic centre inhibits F-actin-stimulated myosin ATPase activity, Biochemistry 43, 5551-5561.

36. Pires, E., Perry, S. V., and Thomas, M. A. (1974) Myosin lightchain kinase, a new enzyme from striated muscle, FEBS Lett. 41 , 292-296.

37. Pardee, J. D., and Spudich, J. A. (1982) Purification of muscle actin, Methods Enzymol. 85, 164-181.

38. Martin-Romero, F. J., Gutierrez-Martin, Y., Henao, F., and Gutierrez-Merino, C. (2002) The NADH oxidase activity of the plasma membrane of synaptosomes is a major source of superoxide anion and is inhibited by peroxynitrite, J. Neurochem. 82, 604-614.

39. Cuenda, A., Henao, F., and Gutierrez-Merino, C. (1990) Distances between functional sites of the $\mathrm{Ca}^{2+}+\mathrm{Mg}^{2+}$-ATPase from sarcoplasmic reticulum using $\mathrm{Co}^{2+}$ as a spectroscopic ruler, Eur. J. Biochem. 194, 663-670.

40. Fiske, C. H., and Subbarow, Y. (1925) The colorimetric determination of phosphorus, J. Biol. Chem. 66, 375-400.

41. Merino, J. M., and Gutierrez-Merino, C. (1999) pH and ligand binding modulate the strength of protein-protein interactions in the $\mathrm{Ca}^{2+}$-ATPase from sarcoplasmic reticulum membranes, Biochim. Biophys. Acta 1420, 203-213.

42. Gutierrez-Merino, C. (1987) Gel to liquid crystalline phase transition promotes a conformational reorganization of $\mathrm{Ca} 2+$, $\mathrm{Mg} 2+-\mathrm{ATPase}$ from sarcoplasmic reticulum in dimyristoylphosphatidylcholine reconstituted systems, Arch. Biochem. Biophys. 252, 303-314.

43. Gutierrez-Martin, Y., Martin-Romero, F. J., Henao, F., and Gutierrez-Merino, C. (2002) Synaptosomal plasma membrane $\mathrm{Ca}^{2+}$ pump activity inhibition by repetitive micromolar $\mathrm{ONOO}^{-}$ pulses, Free Radical Biol. Med. 32, 46-55.

44. Dalle-Donne, I., Rossi, R., Giustarini, D., Milzani, A., and Colombo, R. (2003) Protein carbonyl groups as biomarkers of oxidative stress, Clin. Chim. Acta 329, 23-38.

45. Reisler, E. (1982) Sulfhydryl modification and labeling of myosin, Methods Enzymol. 85, 84-93.

46. VanDuijn, M. M., Tijssen, K., VanSteveninck, J., Van Den Broek, P. J., and Van Der Zee, J. (2000) Erythrocytes reduce extracellular ascorbate free radicals using intracellular ascorbate as an electron donor, J. Biol. Chem. 275, 27720-27725.

47. Kirsch, M., and de Groot, H. (1999) Reaction of peroxynitrite with reduced nicotinamide nucleotides, the formation of hydrogen peroxide, J. Biol. Chem. 274, 24664-24670.

48. Perkins, W. J., Han, Y.-S., and Sieck, G. C. (1997) Skeletal muscle force and actomyosin ATPase activity reduced by nitric oxide donor, J. Appl. Physiol. 83, 1326-1332.

49. Kirsch, M., Lomonosova, E. E., Korth, H. G., Sustmann, R., and de Groot, H. (1998) Hydrogen peroxide formation by reaction of peroxynitrite with HEPES and related tertiary amines. Implications for a general mechanism, J. Biol. Chem. 273, 12716-12724.

50. Gutierrez-Martin, Y., Martin-Romero, F. J., Inesta-Vaquera, F. A., Gutierrez-Merino, C., and Henao, F. (2004) Modulation of sarcoplasmic reticulum $\mathrm{Ca}^{2+}$-ATPase by chronic and acute exposure to peroxynitrite, Eur. J. Biochem. 271, 2647-2657.

51. Sekine, T., Barnett, L. M., and Kielley, W. W. (1962) The active site of myosin adenosine triphosphatase. I. Localization of one of the sulfhydryl groups, J. Biol. Chem. 237, 2769-2772.

52. Yamaguchi, M., and Sekine, T. (1966) Sulfhydryl groups involved in the active site of myosin A adenosine triphosphatase. I. Specific blocking of the $\mathrm{SH}$ group responsible for the inhibitory phase in "biphasic response" of the catalytic activity, J. Biochem. (Tokyo) $59,24-33$.

53. Rayment, I., Rypniewski, W. R., Schmidt-Base, K., Smith, R., Tomchick, D. R., Benning, M. M., Winkelmann, D. A., Wesenberg, G., and Holden, H. M. (1993) Three-dimensional structure of myosin subfragment-1: a molecular motor, Science 261, 5058.

54. Rayment, I. (1996) The structural basis of the myosin ATPase activity, J. Biol. Chem. 271, 15850-15853.

55. Freire, E., van Osdol, W. W., Mayorga, O. L., and Sanchez-Ruiz, J. M. (1990) Calorimetrically determined dynamics of complex unfolding transitions in proteins, Annu. Rev. Biophys. Biophys. Chem. 19, 159-188.

56. Bobkov, A. A., and Levitsky, D. I. (1995) Differential scanning calorimetric study of the complexes of myosin subfragment 1 with nucleoside diphosphates and vanadate or beryllium fluoride, Biochemistry 34, 9708-9713.

57. Nikolaeva, O. P., Orlov, V. N., Bobkov, A. A., and Levitsky, D. I. (2002) Differential scanning calorimetric study of myosin subfragment 1 with tryptic cleavage at the $\mathrm{N}$-terminal region of the heavy chain, Eur. J. Biochem. 269, 5678-5688.

58. Nikolaeva, O. P., Orlov, V. N., Dedova, I. V., Drachev, V. A., and Levitsky, D. I. (1996) Interaction of myosin subfragment 1 with F-actin studied by differential scanning calorimetry, Biochem. Mol. Biol. Int. 40, 653-661.

59. Schroeder, P., Klotz, L. O., Buchczyk, D. P., Sadik, C. D., Schewe, T., and Sies, H. (2001) Epicatechin selectively prevents nitration but not oxidation reactions of peroxynitrite, Biochem. Biophys. Res. Commun. 285, 782-787.

60. Lowey, S., Slayter, H. S., Weeds, A. G., and Baker, H. (1969) Substructure of the myosin molecule. I. Subfragments of myosin by enzymic degradation, J. Mol. Biol. 42, 1-29.

61. Buettner, G. R., and Jurkiewicz, B. A. (1996) Catalytic metals, ascorbate and free radicals: combinations to avoid, Radiat. Res. $145,532-541$.

62. Mihm, M. J., and Bauer, J. A. (2002) Peroxynitrite-induced inhibition and nitration of cardiac myofibrillar creatine kinase, Biochimie 84, 1013-1019.

63. Arteel, G. E., Briviba, K., and Sies, H. (1999) Protection against peroxynitrite, FEBS Lett. 445, 226-230.

64. Kirsch, M., and De Groot, H. (2001) NAD(P)H, a directly operating antioxidant? FASEB J. 15, 1569-1574.

65. Morre, D. J. (1994) Hormone- and growth factor-stimulated NADH oxidase, J. Bioenerg. Biomembr. 26, 421-433.

66. Herrero, A., and Barja, G. (2000) Localization of the site of oxygen radical generation inside the complex I of heart and nonsynaptic brain mammalian mitochondria, J. Bioenerg. Biomembr. 32, 609615.

67. Davies, K. J. (2001) Degradation of oxidized proteins by the $20 \mathrm{~S}$ proteasome, Biochimie 83, 301-310.

68. Grune, T., Merker, K., Sandig, G., and Davies, K. J. (2003) Selective degradation of oxidatively modified protein substrates by the proteasome, Biochem. Biophys. Res. Commun. 305, 709718 .

69. Grune, T., Blasig, I. E., Sitte, N., Roloff, B., Haseloff, R., and Davies, K. J. (1998) Peroxynitrite increases the degradation of aconitase and other cellular proteins by proteasome, J. Biol. Chem. $273,10857-10862$.

\section{BI0518500}

